\title{
Copper Removal by Acid-Conditioned Zeolite, Part I: Equilibrium, and Numerical Simulations
}

\author{
Andrés Avelino Abin-Bazaine ${ }^{1} \quad$ Gilberto Sandino Aquino-De Los Ríos ${ }^{1} \quad$ Luis Miguel Rodríguez-Vázquez ${ }^{2}$ \\ Eduardo Santellano-Estrada ${ }^{1} \quad$ Sandra Rodríguez-Piñeros ${ }^{1} \quad$ Leonor Cortés-Palacios*,1 \\ 1.Facultad de Zootecnia y Ecología, Universidad Autónoma de Chihuahua. Perif. Francisco R. Almada Km. 1. \\ Chihuahua, Chih., México \\ 2. Instituto Tecnológico de Parral. Avenida Tecnológico No. 57. Hidalgo del Parral, Chihuahua, México.
}

\begin{abstract}
Heavy metal water pollution is one of the most pressing environmental problems of the last decades. Wastewater from many industrial processes contain high concentrations of metals and have very acid $\mathrm{pH}$. Thus, technologies to remove heavy metals from aqueous solutions are costly or suffer deterioration when in contact with substances with acid $\mathrm{pH}$. Natural zeolites have demonstrated to be a low-cost heavy metal adsorbent. This study aimed to determine basic parameters for efficient copper removal by aluminosilicates. A Zeolite was conditioned with concentrated $\mathrm{H}_{2} \mathrm{SO}_{4}$ to further develop the experiments to test 12 equilibrium isotherms (Freundlich, RedlichPaterson, Sips, Halsey, Dubinin-Radushkevich, Flory-Huggins, Langmuir, Temkin, Elovich, Fowler-Guggenheim, Henry's and Kiselev) and pHpzc. Maximum removal was obtained with neutral pH values; the Freundlich model had the best performance. The removal efficiency increased as the initial concentration of the solution increased. The $\mathrm{pH}$ value at the point of zero charge was 2.9 .
\end{abstract}

Keywords: Isotherms; Aluminosilicates, Metals, Freundlich, Numerical Simulations

DOI: $10.7176 / \mathrm{JEES} / 9-3-03$

Publication date:March $31^{\text {st }} 2019$

\section{Introduction}

The term heavy metal is used to describe a group of elements that have an atomic density greater than $6 \mathrm{~g} \mathrm{~cm}^{-3}$; these are the major pollutants of water reservoirs due to their toxicity, non-biodegradation and their persistence in the environment (Meng, Chen, Lin, Lin, \& Sun, 2017; Xiyili, Çetintaş, \& Bingöl, 2017). Heavy metals can cause serious environmental and health problems; therefore, any effort to eliminate heavy metals from water sources is crucial (Choi, Yu, \& Kim, 2016; Y. Wu \& Wang, 2016). Copper is a metal widely used in various industries, such as silver-plating, mining and smelting, bronze fabrication, electrodeposition industries, petroleum refining and agrochemical manufacturing, producing massive quantities of wastewater and sludge that contains $\mathrm{Cu}(\mathrm{II})$ ions at various concentrations that have negative effects on the aquatic environment and human health. The maximum daily permissible level for the discarding of copper on a body of water in accordance with Mexican regulations is $6 \mathrm{mg} \mathrm{L}^{-1}$ (NOM-001-SEMARNAT-1996); in the USA, the maximum daily level is $4.14 \mathrm{mg} \mathrm{L}^{-1}$ (Electronic Code of Federal Regulations (e-CFR), Title 40. Protection of Environment, Chapter I. Environmental Protection Agency, Subchapter N. Effluent Guidelines and Standards, Part 437. The Centralized Waste Treatment Point Source Category, Subpart A. Metals Treatment and Recovery, Section 437.11. Effluent Limitations Attainable by The Application Of The Best Practicable Control Technology Currently Available (BPT)). Copper can also be found as a contaminant in foods, especially seafood, beef liver, mushrooms, and nuts. The toxicity of copper in humans has been thoroughly reviewed by some researchers. Acute copper poisoning by ingestion may show systemic effects such as hemolysis, and liver and kidney damage; irritation of the upper respiratory tract, gastrointestinal disorders with vomiting and diarrhea, in turn, there have been reports of dermatitis due to direct contact with copper. Therefore, it is necessary to treat wastewater containing copper before discharging it into the streams (Demiral \& Güngör, 2016). Traditional treatment technologies for the removal of heavy metals include a combination of chemical, physical, and biological methods but these require high investment and consequently elevated maintenance costs (Choi et al., 2016; Meng et al., 2017; Zhou, Yang, Liu, \& Kong, 2015). A promising alternative, especially in emerging economies, is the use of bioadsorbents or natural zeolites since they present low cost compared to synthetic sorbents. Zeolites are highly porous minerals of aluminosilicates that are formed from a three-dimensional tetrahedral crystal structure of alumina $\left(\mathrm{AlO}_{4}\right)$ and silica $\left(\mathrm{SiO}_{4}\right)$. The aluminum ion is small and occupies the position in the center of the tetrahedron of four oxygen atoms, its isomorphic replacement of $\mathrm{Si}^{4+}$ and $\mathrm{Al}^{3+}$ produces a negative charge in the lattice and forms an open structure with long channels through which water and other molecules can be accommodated exhibiting considerable freedom of movement, allowing ion exchange and reversible hydration (Choi et al., 2016; Zanin et al., 2017). Substitution of $\mathrm{Si}^{4+}$ by $\mathrm{Al}^{3+}$ defines the negative charge of the zeolite framework, which is compensated by alkaline and earth-alkaline metal cations (Margeta, Zabukovec, Siljeg, \& Farkas, 2013; S. Wang \& Peng, 2010a). Zeolites behave as cation exchangers because they have negative charge on the surface (Margeta et al., 2013; S. Wang \& Peng, 2010a). The acid washing of the natural zeolite can remove the impurities that obstruct the pores, improving the possibility that contaminants 
are in contact with the zeolite pores (S. Wang \& Peng, 2010b). An acid treatment to a zeolite, which supplies $\mathrm{H}^{+}$, causes a partial rupture of the $\mathrm{Al}-\mathrm{O}-\mathrm{Al}$ and $\mathrm{Al}-\mathrm{O}-\mathrm{Si}$ bonds through the dealuminization, as indicated by lower $\mathrm{Si} / \mathrm{Al}$ ratios, with this it is suggested that the Al-O- and Si-O-dealuminizated bonds are potential ion exchange sites (Paul, Dynes, \& Chang, 2017). Zeolites can be modified by means of treatments such as chemical attacks. An acidic treatment can improve its adsorption capacity and expand its pore system. Acid attack dealuminizes the structure because it attacks and weakens Al-O bonds, causing defects and vacancies in the skeleton. These treatments increase the size and quantity of the zeolite pores, increasing the surface area and adsorption capacity. Acid treatment can be used as a simple and economical method to increase the adsorption capacity of natural zeolites (X. Wang, Ozdemir, Hampton, Nguyen, \& Do, 2012). The drainages produced by mining are usually very acidic $\mathrm{pH}$, which can have an effect on the crystalline structure of zeolites; therefore, it is important to know the degree of affectation of the adsorption capacity of a zeolite (Clinoptilolite) once it has been put in contact with a solution with extreme acidic $\mathrm{pH}$ values. Solution $\mathrm{pH}$ affects both the adsorbent aqueous chemistry and surface binding sites (Demiral \& Güngör, 2016). The objective of this study was to determine the basic design parameters of a treatment process for copper removal and the degree of affectation of the adsorption capacity after acidconditioning.

\section{Materials and Methods}

2.1 Reagents

All the reagents used for the preparation of the standard solutions were made with reactive grade products. The $\mathrm{Cu}$ (II) standard solution was prepared with Penta Hydrated Copper Sulphate $\left(\mathrm{CuSO}_{4} \cdot 5 \mathrm{H}_{2} \mathrm{O}\right)$.

\subsection{Preparation of the adsorbent material}

For this study, a mineral zeolitic material extracted from a deposit that is located in the vicinity of the city of Aldama, Chihuahua, Mexico (28 $48^{\circ} 36^{\prime \prime} \mathrm{N}, 105^{\circ} 54^{\prime} 3.0^{\prime \prime} \mathrm{W}$ ) was used. The samples were crushed and passed through a metal sieve. The material that went through a No. 10 mesh (U.S. STD. Sieve), with an opening of $2 \mathrm{~mm}$ was used for the study. The samples were conditioned by an immersion in concentrated sulfuric acid $\left(\mathrm{H}_{2} \mathrm{SO}_{4}\right)$ for 24 hours, after conditioning they were decanted and washed with distilled water and dried in an oven.

\subsection{Characterization of the adsorbent material}

The material was characterized using an X-ray spectrophotometer PAN analytical model (X'Pert PRO MPDX'Celerator), finding an abundant presence of clinoptilolite, tosudite, calcite and quartz, as well as other elements at lower concentrations such as cristobalite, sanidine and sodium anorthite (López-Aguilar, HuertaReynosoa, , J.A. Gómez, Duarte-Moller, \& Pérez-Hernández, 2016).

\subsection{Methodology}

All laboratory material was presoaked with $5 \% \mathrm{HNO}_{3}$, then rinsed with distilled water and dried in the oven at 106 ${ }^{0} \mathrm{C}$. The batch tests were carried out in a $150 \mathrm{~mL}$ Erlenmeyer flask and mixed in an oscillatory shaker. Adsorption experiments were carried out in triplicate at a constant agitation speed. $3 \mathrm{~g}$ of zeolite with a variation no greater than $+/-0.005 \mathrm{~g}$ was added to $100 \mathrm{ml}$ of the solution of known concentration. The $\mathrm{pH}$ values were adjusted with $\mathrm{HNO}_{3}$ and $\mathrm{NaOH} 0.1 \mathrm{~N}$ according to the case and with the necessary amount until the desired $\mathrm{pH}$ value was adjusted. Once the test was finished, the samples were separated on Number 1 Whatman filter paper. The concentration of residual metals was measured by ICP-OES Perkin Elmer OPTIMA 8300. The percentage of removal was calculated with the following expression:

$$
\begin{aligned}
& \% \text { Re moval }=\frac{C i-C f}{C i} * 100 \\
& q e=\frac{C i-C f}{m} * V
\end{aligned}
$$

\subsection{Sorption Studies}

\subsubsection{Effect of the $\mathrm{pH}$ of the solution}

A 7-level, 3-repetition one-way experimental test was performed. The $\mathrm{pH}$ values used were 2, 3, 4, 5, 6, 7 and 8 . To $100 \mathrm{~mL}$ of solution at $50 \mathrm{mg} \mathrm{L}^{-1} \mathrm{Cu}(\mathrm{II})$ concentration $6 \mathrm{~g}$ of the adsorbent material was added and the mixture was stirred for 24 hours to ensure that the equilibrium was reached.

\subsubsection{Maximum Sorption Capacity}

A constant mass of $3 \mathrm{~g}$ of zeolite was used in a volume of $100 \mathrm{~mL}$ of a solution containing a specific concentration. The $\mathrm{pH}$ value was adjusted to the optimum range obtained in concentration diagram of copper species in aqueous solution, the range was 4.0-4.5. A 5-level, 3-repetition one-way experimental test was performed to observe the reproducibility of the results; the average value obtained in this procedure was used. The concentrations used for each metal were $50,100,150,200$ and $250 \mathrm{mg} \mathrm{L}^{-1}$. The agitation time was 24 hours. The $\mathrm{pH}$ was adjusted to the range 4.0-4.5. 


\subsubsection{Determination of $\mathrm{pH}_{\mathrm{pzc}}$}

The $\mathrm{pH}$ value at which the net surface charge was zero is known as $\mathrm{pH}_{\mathrm{PZC}}$. At $\mathrm{pH}<\mathrm{pHpzc}$, the zeolite surface has a net positive charge, while at $\mathrm{pH}>\mathrm{pHpzc}$ the surface has a net negative charge (Al-Degs, El-Barghouthi, ElSheikh, \& Walker, 2008a; Chutia, Kato, Kojima, \& Satokawa, 2009; Fiol \& Villaescusa, 2009; Mohammadian, Rabieh, \& Zavvar, 2018). The knowledge of point of zero charge of the studied materials provides information about the possible attraction and repulsion between sorbent and sorbate (Fiol \& Villaescusa, 2009). For the determination of the $\mathrm{pH}$ at the point of zero charge $(\mathrm{pHpzc})$ the equilibrium batch method was used, also known as the conventional method (Kalhori, Al-Musawi, Ghahramani, Kazemian, \& Zarrabi, 2017; Zavareh, Farrokhzad, \& Darvishi, 2018). A series of solutions of $\mathrm{NaCl} 0.1 \mathrm{M}$ had their $\mathrm{pH}$ value adjusted in a range between 2 to 11 by adding diluted $\mathrm{HNO}_{3}$ or $\mathrm{NaOH}$. The exact value of each of the solutions is called the initial $\mathrm{pH}(\mathrm{pH})$. A sample of the zeolite $(0.2 \mathrm{~g})$ was weighed and added to a volume of $100 \mathrm{~mL}$ of the aforementioned solutions. The suspensions were shaken for 48 hours at room temperature to ensure their complete equilibrium. Once the agitation was finished, the samples were filtered to separate the adsorbent and the liquid phase; the final $\mathrm{pH}$ value $\left(\mathrm{pH}_{\mathrm{f}}\right)$ was quantified. The $\mathrm{pH}_{\mathrm{pzc}}$ is the point where the curve of $\mathrm{pH}_{\mathrm{f}}$ versus $\mathrm{pH}_{\mathrm{i}}$ intersects the plot line $\mathrm{pH}_{\mathrm{i}}=\mathrm{pH}_{\mathrm{f}}(\mathrm{Al}$-Degs, El-Barghouthi, El-Sheikh, \& Walker, 2008b; Mourid, Lakraimi, El Khattabi, Benaziz, \& Berraho, 2017; Sun, Zhang, Wang, \& Wu, 2013; Tabassi, Harbi, Louati, \& Hamrouni, 2017).

2.5.4 Evaluation of the Fitness of Isothermal Equations against Experimental Data

2.5.4.1 Average Relative Error (\%ARE)

To evaluate the suitability of the isothermal equations against the data obtained experimentally, the Relative Error Average (\%ARE) was used, using the following equation:

$$
\% A R E=\frac{100}{n} \sum_{i=1}^{n}\left\|\frac{q_{i, c a l}-q_{i, \exp }}{q_{i, \exp }}\right\|
$$

Where: $\mathrm{n}$ is the data number, $\mathrm{q}_{\mathrm{i}, \mathrm{cal}}$ are the equilibrium values calculated with the mathematical expression $\left(\mathrm{mg} \mathrm{g}^{-1}\right)$ and $\mathrm{q}_{\mathrm{i} \text { exp }}$ are values obtained experimentally $\left(\mathrm{mg} \mathrm{g}^{-1}\right)$ (Demiral \& Güngör, 2016; Rajabi et al., 2016; Rangabhashiyam, Anu, Giri Nandagopal, \& Selvaraju, 2014). An average relative error lower or equal than 5\% was considered adequate.

\subsubsection{Chi-square $\left(\chi^{2}\right)$}

To identify the best fitted isotherm model, we examined the linear Chi-square values $(\chi 2)$ along with the linear regressions $\left(\mathrm{R}^{2}\right)$. The Chi-square statistical test is basically the sum of the squared errors of the differences between the experimental data and the data obtained by calculations using the models. Each square difference is divided by the corresponding data obtained by calculations using the models. If the values obtained using a model are similar to the experimental values, the value of $\chi 2$ will be very small and close to zero. High values of $\chi 2$ imply a high bias between the experiment and the model. Therefore, analyzing the data set of the Chi-square test possibly confirms the isotherm that best fits the Sorption system. The mathematical expression of the Chi-square test is explained below (Tran, You, \& Chao, 2016).

$$
\chi^{2}=\sum_{i=1}^{n} \frac{(q i, e x p-q i, c a l)^{2}}{q i, c a l}
$$

If values $\chi 2 \leq 0.05$ between the experimental data and the data obtained by calculations using the models then they have a statistically significant association.

\section{Results and Discussion}

\subsection{Effect of $\mathrm{pH}$ and $\mathrm{pHpzc}$}

The $\mathrm{pH}$ value at which the net surface charge is zero, is known as $\mathrm{pH}_{\mathrm{PZC}}$. When $\mathrm{pH}<\mathrm{pHpzc}$, the zeolite surface has a net positive charge, and when $\mathrm{pH}>\mathrm{pHpzc}$ the surface has a net negative charge(Al-Degs et al., 2008b; Chutia et al., 2009; Fiol \& Villaescusa, 2009; Mohammadian et al., 2018). The pHpzc is the point where the curve $\mathrm{pH}_{\text {final }}$ vs $\mathrm{pH}_{\text {initial }}$ intersects the line $\mathrm{pH}_{\text {initial }}=\mathrm{pH}_{\text {final }}$ (Al-Degs et al., 2008b). The knowledge of point of zero charge of the studied materials provides information about the possible attraction and repulsion between sorbent and sorbate (Fiol \& Villaescusa, 2009). The point of zero charge is the $\mathrm{pH}$ at which the surface of adsorbent is globally neutral, i.e., contains as much positively charged as negatively charged surface functions. Below this value, the surface is positively charged; above this value, it is negatively charged. So normally, it is always easier to adsorb a cation on a negatively charged surface, and an anion on a positively charged surface. However, other interactions may be stronger than purely electrostatic forces, making the effect of surface charge not so important. Additionally, a cation is often complexed with ligands, some of them being possibly negatively charged. Therefore, in such a case, the cation is in fact a negative complex, which may adsorb very well on a positively charged surface. The surface chemistry of any material is determined by the acidic or basic character of their surface. It knows that acidic means a positive surface charge and basic means negative surface charge. So, it is very important to know the surface charge of the material in the aqueous media, especially in adsorption studies because a high surface area material may be produced but if the surface charge of the material is opposite to adsorption due to the fact of being the same charge as the adsorbate, then the $\mathrm{pH}$ conditions must be modified and $\mathrm{pH}$ conditions that show the best adsorption must be found. The $\mathrm{pH}$ at which the surface charge of the material is zero in the aqueous media must 
also be found, or in other words the pHpzc (pHpoint of zero charge) of the adsorbent material. To determine pHpzc or the $\mathrm{pH}$ where the surface charge of the adsorbent material is zero, the $\mathrm{pH}$ drift method was used, which graphs the final $\mathrm{pH}$ (y axis) vs Initial $\mathrm{pH}$ (x axis). The $\mathrm{pH}$ is an important factor for the sorption process (Ben-Ali, Jaouali, Souissi-Najar, \& Ouederni, 2017; Zanin et al., 2017). To determine the range of values where copper sorption was favored, tests were carried out in batches maintaining constant the temperature, stirring, contact time, metal concentration, and adsorbent dose. Figure 1 shows the removal efficiency (\%) and quantity of sorbed $\mathrm{Cu}$ (II) per gram of zeolite versus $\mathrm{pH}$. The $\mathrm{pH}$ value that reached the highest copper removal was 7 , but it is important to emphasize that the values of removal obtained with the values of $\mathrm{pH} 6,7$ and 8 do not present significant differences from the statistical point of view with a value of significance of $5 \%$. According to a diagram of $\mathrm{pH}$ dependent copper species, it is observed that copper at a $\mathrm{pH}$ value $\geq 5.5$ begins to precipitate, whereby the removal of the copper is done by the precipitation of the same; it is necessary to take care that its precipitation is not quantified as a removal by adsorption. When the $\mathrm{pH}$ range was between $2-5$, the removal capacity remained very low and there were very slight increases in the removal, but an abrupt increase was observed when the $\mathrm{pH}$ value increased to 6 . The low removal capacity at low values $\mathrm{pH}$ may be due to a competition between hydrogen ions and metal ions for the same sorption sites (Ben-Ali et al., 2017; Demirbas, 2009). When alkaline pH values were achieved, the sorption capacity decreased with respect to the values obtained in the neutrality. At high $\mathrm{pH}$ values, sorption decreased since the exchange sites were not activated under basic conditions (Hossain, Ngo, Guo, \& Nguyen, 2012). In our results, the $\mathrm{pH}$ value at which the maximum removal is achieved is the neutral, remaining practically constant with increasing $\mathrm{pH}$, this behavior agrees with the findings of by Abdel Salam et. al. (2011), since in their study the sorption capacity remained constant, although the $\mathrm{pH}$ value increased. Previous studies (Hossain et al., 2012; Ltaief, Siffert, Fourmentin, \& Benzina, 2015) found that the removal of this metal reached its maximum sorption in neutral values and decreased with increasing $\mathrm{pH}$ values, which is contrary to what was in this study. Ksakas et. al. (2018) found that the $\mathrm{pH}$ at which the maximum sorption was achieved was placed in 6 units. Hesnawi et. al. (2017) concluded that the elimination efficiency for copper increased strongly from $7 \%$ to $99 \%$ in a pH range of 2.0 to 7.0 , and then no further elimination was observed at a $\mathrm{pH}$ higher than 7.0 , our results observed that the removal was directly proportional to the increase in the $\mathrm{pH}$ value, staying unaltered by increasing the $\mathrm{pH}$. Kocaoba et. al. (2007) found that at a $\mathrm{pH}$ value of 6 , the removal of copper was $88.9 \%$ and in this study for that same $\mathrm{pH}$ value the removal was $95.89 \%$. Zanin et. al. (2017), conducted an assay to remove copper from an effluent of the graphic printing industry by means of zeolites, removing $96 \%$ at a $\mathrm{pH}$ of 4.0 , in the present study at that $\mathrm{pH}$ value only $33.18 \%$ was removed, but at a value of $7,96.88 \%$ was removed; the variations were attributed to the difference of the liquid matrix from which the metal in question is adsorbed. Wang et. al. (2008) found that the maximum sorption capacity was reached at a $\mathrm{pH}$ value of 7 , coinciding with the findings of this study. Figure 2 shows the determination of pHpzc. From this figure the value of $\mathrm{pHpzc}=2.9$ was obtained. In a previous study, the $\mathrm{pH}_{\mathrm{PZC}}$ value in a zeolite was determined after an acid treatment was performed and the value decreased from 7.9 without treatment to 2.7 with treatment (Valdés, Tardón, \& Zaror, 2010). The electrical charge of the natural surface of the zeolite depends on the permanent negative charge of its aluminosilicate structure, due to the isomorphic substitution of aluminum $\left(\mathrm{Al}^{+3}\right)$ by silicon $\left(\mathrm{Si}^{+4}\right)$ and the $\mathrm{pH}$ of the solution, which influences the protonation/deprotonation of the superficial functional groups. The modification of the functional groups of the surface by chemical pretreatment of the raw ore can change the value of pHpzc (Mitrogiannis et al., 2017). 




Figure 1. Removal efficiency (\%) and quantity of sorbed $\mathrm{Cu}(\mathrm{II})$ per gram of zeolite vs. pHo.

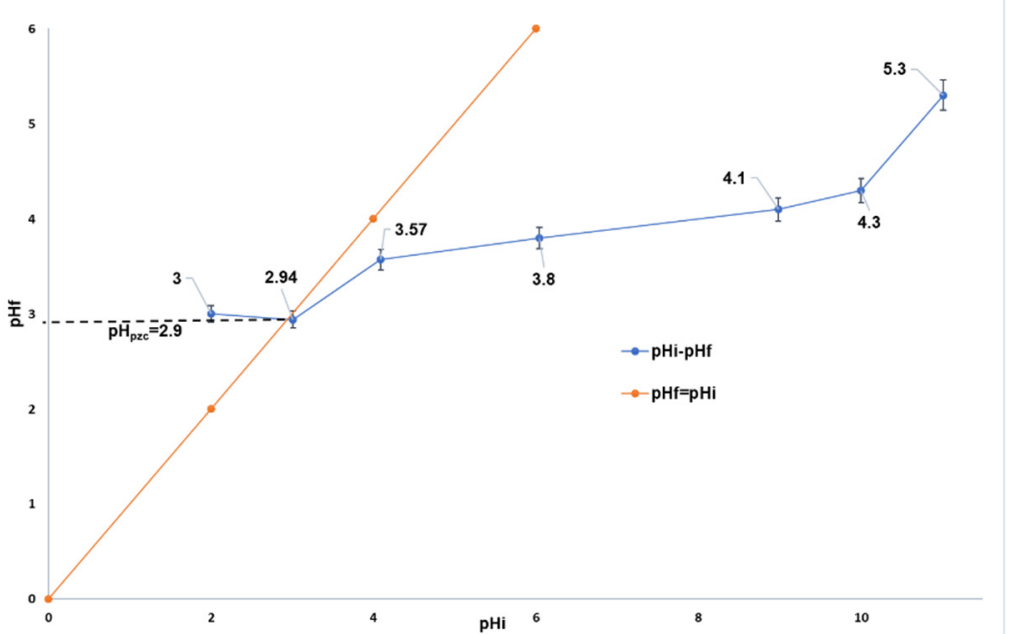

Figure 2. Determination of $\mathrm{pH}$ Point of Zero Charge for Acid Activated Zeolite

\subsection{Amount of $\mathrm{Cu}(I I)$ sorbed and removal efficiency (\%) on the zeolite at different initial concentrations}

The amount of copper removed per unit mass of adsorbent increases as the initial concentration increases, this since the amount removed is given as a function of the initial and final concentrations; if increasing these amounts, but keeping the amount of adsorbent constant, is reflected in an increase in the amount of sorbed metal ion per unit mass of the adsorbent, however, the percentage of removal decreases this because there are no more surface exchange sites of the adsorbent, this behavior was similar to that presented by Abdel Salam et. al. 2011. Figure 3 shows the amount of copper sorbed and the removal efficiency by the zeolite at different initial concentrations of the same metal. 


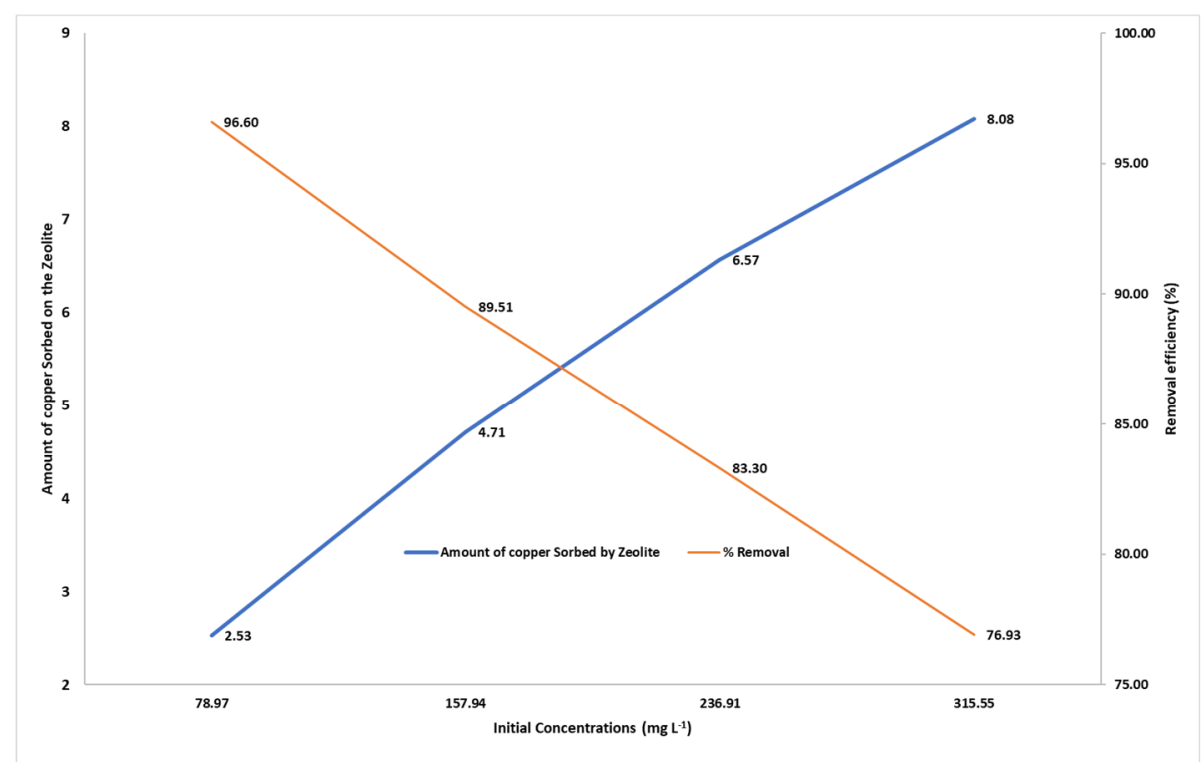

Figure 3. Amount of $\mathrm{Cu}(\mathrm{II})$ sorbed and removal efficiency (\%) on the zeolite at different initial concentrations

\subsection{Sorption Isotherms}

The equilibrium data, which are generally known as sorption isotherms, are the main requirement for the understanding of the sorption mechanisms. The sorption isotherms are important to describe how the adsorbate molecules or ions interact with superficial adsorption sites. Therefore, the correlation of the data in equilibrium using either a theoretical or empirical equation is essential for adsorption interpretation and prediction (Demiral \& Güngör, 2016). Adsorption isotherms are expressed in an equation in which the relationship between the amount of the solute adsorbed by the adsorbent and the concentration of the solute in the liquid phase, they are important because they describe how an adsorbate interacts with an adsorbent and these are critical for the design of an adsorption process. Several isotherm models have been developed to describe the relationship of the metal concentration that has been adsorbed on the solid phase with metal concentration in the solution in equilibrium for a specific temperature (Abdel Salam, Reiad, \& ElShafei, 2011; Demiral \& Güngör, 2016; Ghasemi, Javadian, Ghasemi, Agarwal, \& Gupta, 2016; Gupta, Mittal, \& Mittal, 2012; Kim, Park, \& Park, 2015; Li et al., 2015; Lin, Zhan, \& Zhu, 2011; Malamis \& Katsou, 2013; Motsi, Rowson, \& Simmons, 2009; Park, Yun, \& Park, 2010; Shukla, Wang, Ang, \& Tadé, 2009), models used are Henry's, Langmuir, Freundlich, Temkin, DubininRadushkevich (D-R), Redlich-Paterson, Sips, Halsey, Harkins-Jura, Elovich, Flory-Huggins, Fowler-Guggenheim, Jovanovic and Kiselev. In almost all adsorption studies of metals with zeolites, Freundlich and Langmuir were the isotherms models used (Abdel Salam et al., 2011; Erdem, Karapinar, \& Donat, 2004; Hesnawi, R. Jamal, F. Eswayah, A. Maga, 2017; Kocaoba, Orhan, \& Akyüz, 2007; Ksakas, Tanji, El Bali, Taleb, \& Kherbeche, 2018; Ltaief et al., 2015; Merrikhpour \& Jalali, 2013; Panayotova, 2001; Sprynskyy, Buszewski, Terzyk, \& Namiesnik, 2006; Taamneh \& Sharadqah, 2017; Zanin et al., 2017) which are the most often used to predict the maximum adsorption capacity (Moussout, Ahlafi, Aazza, \& Maghat, 2018).

3.3.1 Henry's isotherm

This isotherm model appropriately describes the adsorption process for low concentrations, such that none of the adsorbate molecules have interaction with adjacent molecules (Ayawei, Ebelegi, \& Wankasi, 2017). The concentrations in the phases are related to a linear expression. It is expressed with:

$$
q_{e}=K_{H E} C_{e}
$$

Where: qe is the quantity of $\mathrm{Cu}(\mathrm{II})$ ions sorbed per gram of zeolite $\left(\mathrm{mg} \mathrm{g}^{-1}\right)$; $\mathrm{K}_{\mathrm{HE}}$ is the equilibrium constant of Henry's and $\mathrm{Ce}$ is the equilibrium concentration of the metal ions in the solution $\left(\mathrm{mg} \mathrm{L}^{-1}\right)$.

Figure 4 shows the graph of Henry's model, the value of $\mathrm{R}^{2}, \% \mathrm{ARE}$ and $\chi^{2}$ are not satisfactory (Table 1). The results indicate that the copper adsorption does not present a linear behavior. 


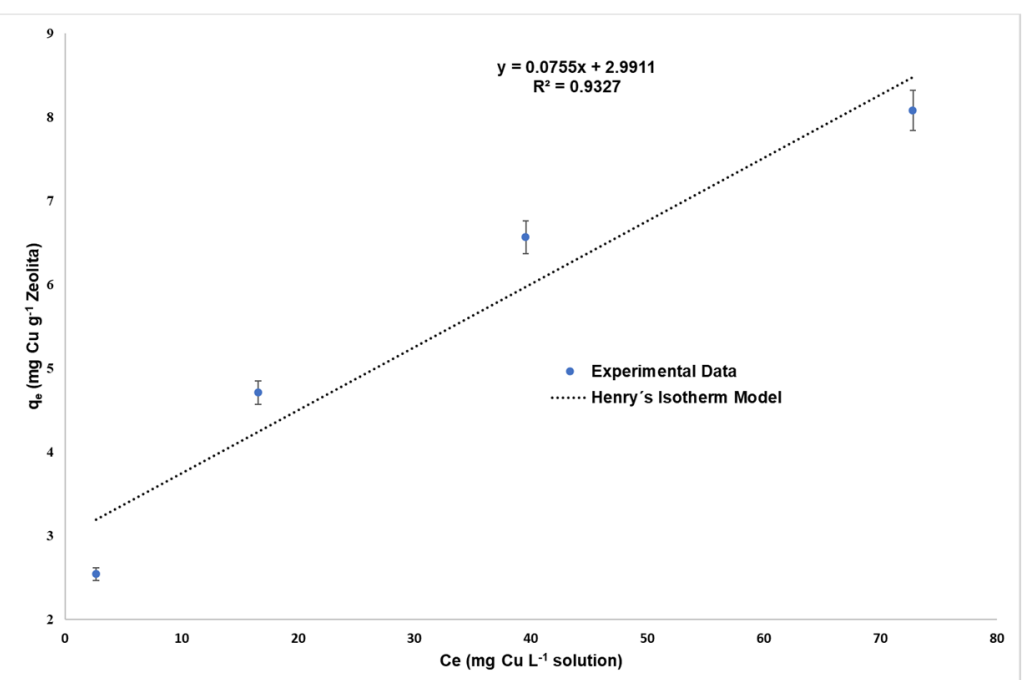

Figure 4. Henry's Isotherm Model for $\mathrm{Cu}(\mathrm{II})$ onto Zeolite.

\begin{tabular}{|c|c|c|c|c|c|}
\hline MODEL & \multicolumn{2}{|c|}{ Parameter } & MODEL & \multicolumn{2}{|c|}{ Parameter } \\
\hline \multirow[t]{4}{*}{ Henry's } & $\mathrm{K}_{\mathrm{HE}}$ & 0.076 & \multirow{6}{*}{$\begin{array}{l}\text { Redlich- } \\
\text { Paterson }\end{array}$} & $\mathrm{K}_{\mathrm{R}}$ & 22.420 \\
\hline & $\mathrm{R}^{2}$ & 0.934 & & $\alpha R$ & 12.310 \\
\hline & $\chi^{2}$ & 4.160 & & $\beta$ & 0.615 \\
\hline & \%ARE & 1344.000 & & $\mathrm{R}^{2}$ & 1.000 \\
\hline \multirow[t]{6}{*}{ Langmuir } & $\mathrm{q}_{\mathrm{m}}$ & 9.080 & & $\chi^{2}$ & 0.003 \\
\hline & $\overline{\mathrm{K}_{\mathrm{L}}}$ & 0.086 & & \%ARE & 1.420 \\
\hline & $\mathrm{R}_{\mathrm{L}}$ & 0.105 & \multirow[t]{5}{*}{ Sips } & $\mathrm{K}_{\mathrm{s}}$ & 1.789 \\
\hline & $\mathrm{R}^{2}$ & 0.980 & & $\beta_{s}$ & 2.840 \\
\hline & $\chi^{2}$ & 0.530 & & $\mathrm{R}^{2}$ & 0.999 \\
\hline & $\%$ ARE & 14.180 & & $\chi^{2}$ & 0.0003 \\
\hline \multirow[t]{5}{*}{ Freundlich } & $1 / n$ & 0.351 & & $\%$ ARE & 0.610 \\
\hline & $\mathrm{K}_{\mathrm{F}}$ & 1.789 & \multirow[t]{4}{*}{ Halsey } & $\mathrm{n}_{\mathrm{H}}$ & 0.351 \\
\hline & $\mathrm{R}^{2}$ & 0.999 & & $\mathrm{~K}_{\mathrm{H}}$ & 1.074 \\
\hline & $\chi^{2}$ & 0.0001 & & $\mathrm{R}^{2}$ & 0.999 \\
\hline & \%ARE & 0.610 & & $\chi^{2}$ & 0.0003 \\
\hline \multirow[t]{5}{*}{ Temkin } & $B$ & 1.635 & & $\%$ ARE & 0.616 \\
\hline & $\overline{\mathrm{Kt}}$ & 1.055 & \multirow{4}{*}{$\begin{array}{l}\text { Harkins- } \\
\text { Jura }\end{array}$} & $\mathrm{A}_{\mathrm{HJ}}$ & 9.930 \\
\hline & $\mathrm{R}^{2}$ & 0.968 & & $\mathrm{~B}_{\mathrm{HJ}}$ & 1.868 \\
\hline & $\chi^{2}$ & 0.112 & & $\mathrm{R}^{2}$ & 0.942 \\
\hline & $\%$ ARE & 7.250 & & $\chi^{2}$ & 0.321 \\
\hline Dubinin- & $q_{s}$ & 20.150 & & \%ARE & 41.220 \\
\hline \multirow[t]{5}{*}{ Radushkevi } & B & -0.004 & \multirow[t]{5}{*}{ Elovich } & $\mathrm{q}_{\mathrm{m}}$ & 2.608 \\
\hline & $E$ & 11.950 & & $\mathrm{~K}_{\mathrm{E}}$ & 0.832 \\
\hline & $\mathrm{R}^{2}$ & 0.995 & & $\mathrm{R}^{2}$ & 0.964 \\
\hline & $\chi^{2}$ & 0.003 & & $\chi^{2}$ & 0.170 \\
\hline & $\% A R E$ & 2.270 & & $\%$ ARE & 89.160 \\
\hline
\end{tabular}

Table 1. Isotherm model constants and correlation coefficients for $\mathrm{Cu}(\mathrm{II})$ adsorption onto Zeolite 3.3.2 Langmuir isotherm

The Langmuir equation assumes that maximum adsorption corresponds to a mono saturated layer of adsorbate molecules on the surface, that adsorption energy is constant, and that there is no transmigration of the adsorbate on the surface (Abdel Salam et al., 2011). The Langmuir model is expressed in the following equation:

$$
q e=\frac{q m K_{L} C e}{\left[1+K_{L} C e\right]}
$$

Where: $\mathrm{q}_{\mathrm{m}}$ is the maximum adsorption capacity $\left(\mathrm{mg} \mathrm{g}^{-1}\right)$ and $\mathrm{K}_{\mathrm{L}}$ is the Langmuir constant $\left(\mathrm{L} \mathrm{mg}^{-1}\right)$. 
This is one of the four linear forms for the Langmuir model:

$$
\frac{C e}{q e}=\frac{1}{q m K_{L}}+\frac{1}{q m} C e
$$

The values of the constants qm and $\mathrm{K}_{\mathrm{L}}$ are defined by the slope and the intercept point of the adjusted line of graphing on the Ce abscissa and ordinates Ce/qe respectively (Fardjaoui, El Berrichi, \& Ayari, 2017; Kankrej, Kulkarni, \& Borhade, 2017; Subramani \& Thinakaran, 2017; Y. Wu \& Wang, 2016; Zhang, Jin, Shen, Lynch, \& Al-Tabbaa, 2018).

The characteristic of the Langmuir isotherm is that it can express a dimensionless constant called Equilibrium Parameter or Separation Factor, which is expressed with the following equation:

$$
R_{L}=\frac{1}{\left(1+\left(K_{L} C_{i}\right)\right)}
$$

Where: $\mathrm{R}_{\mathrm{L}}$ is the equilibrium parameter.

The $R_{L}$ values indicate what type of adsorption can be expected. $R_{L}>1$ is unfavorable, $R_{L}=1$ the adsorption is linear, $\mathrm{R}_{\mathrm{L}}=0$ is irreversible and $0<\mathrm{R}_{\mathrm{L}}<1$ is favorable for adsorption (Humelnicu, Băiceanu, Ignat, \& Dulman, 2017; Zendelska, Golomeova, Blazev, Krstev, \& Golomeov, 2014). Figure 5 shows the graph for the Langmuir model. The value of $\mathrm{R}^{2}$ is adequate but the values of \%ARE and $\chi^{2}$ are high (Table 1), this model is not very suitable for copper adsorption. With respect to $\mathrm{R}_{\mathrm{L}}$ the values indicate that the adsorption is favorable but the value is near to zero which indicates a possible irreversibility of the adsorption. The values of the Langmuir $\mathrm{K}_{\mathrm{L}}$ and $\mathrm{q}_{\mathrm{m}}$ constants observed in the results of this study and in Panayotova, 2001, are in the same range, not presenting significant differences. For this isotherm model Ksakas et. al. (2018) present very significant differences that could be attributable to the physical-chemical characteristics of the materials. The maximum adsorption capacity

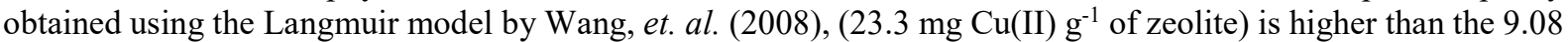
$\mathrm{mg} \mathrm{Cu}(\mathrm{II}) \mathrm{g}^{-1}$ of Zeolite obtained in the results of this study but is within the range of results presented in previous studies. Inglezakis et. al. (2016) determined that the equilibrium of copper in a Zeolite was not favorable being perimetrally opposed to the results of this study.

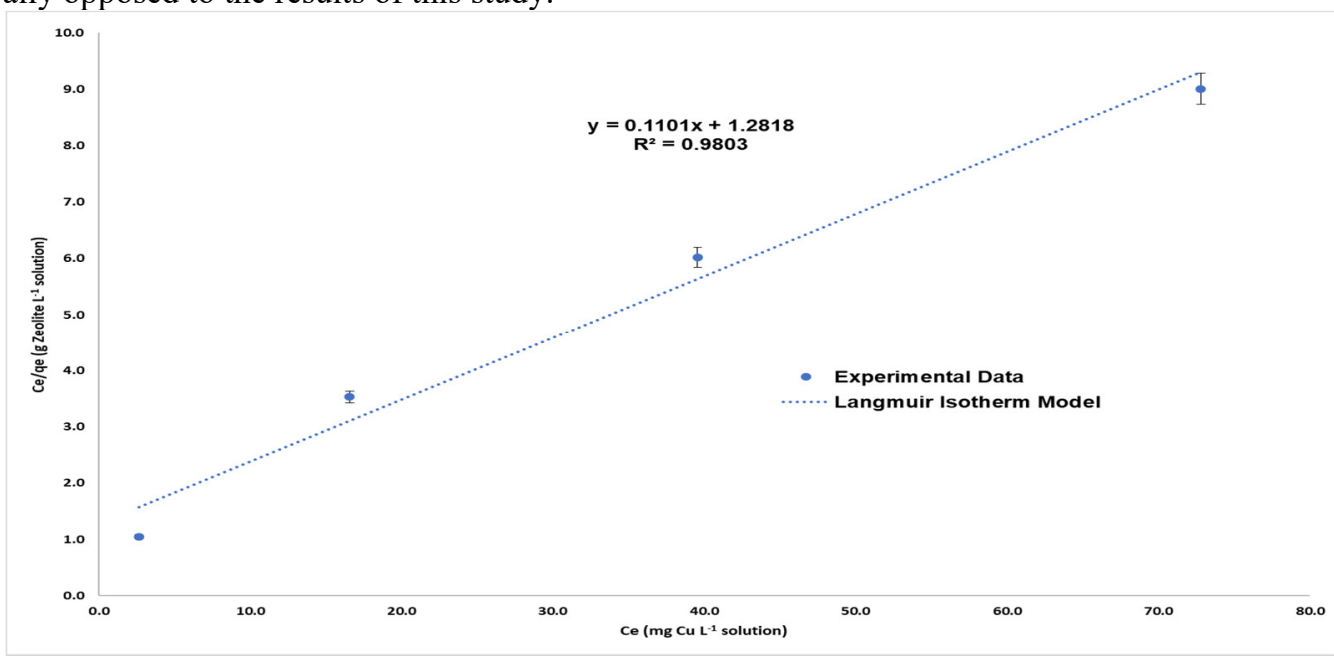

Figure 5. Langmuir Isotherm Model for $\mathrm{Cu}(\mathrm{II})$ onto Zeolite

3.3.3 Freundlich isotherm

The Freundlich model includes the heterogeneity of the surface of the adsorbent and an exponential distribution of the active sites and their energies. The Freundlich model is expressed with the following equation:

$$
q e=K_{F} C_{e}^{1 / n_{F}}
$$

Where: $\mathrm{K}_{\mathrm{F}}$ is the Freundlich constant in $\left(\mathrm{L} \mathrm{g}^{-1}\right)$ and $\mathrm{n}_{\mathrm{F}}$ is the Freundlich exponent related to the intensity of adsorption; is dimensionless.

The equation of this model can be linearized as follows:

$$
\log q e=\log K_{F}+\frac{1}{n_{F}} \log C e
$$

The values of the constants $\left(\mathrm{K}_{\mathrm{F}}\right.$ and $\left.\mathrm{n}_{\mathrm{F}}\right)$ are defined by the intercept and the slope of the graph line in the ordinate $\ln$ qe and in the abscissa $\ln$ Ce respectively. The range of values of $1 / \mathrm{n}_{\mathrm{F}}$ is between 0 and 1 showing the degree of non-linearity between the concentration of the solution and the adsorption. If the value of $1 / \mathrm{n}$ is equal to 1 , the adsorption is linear (Fardjaoui et al., 2017; Kankrej et al., 2017; Subramani \& Thinakaran, 2017; Y. Wu \& Wang, 2016; Zhang et al., 2018). In this case the results show non-linearity on the adsorption onto zeolite. Figure 6 shows the graph for the Freundlich model. The value of $\mathrm{R}^{2}$ is excellent, this model being the one that presents the best fit, with which we can express the existence of a heterogeneous adsorption on the surface of the Zeolite. The values of the suitability coefficients (Table 1) \%ARE and $\chi^{2}$ are very low which indicates a high correlation between the results obtained experimentally and those that calculated from the models. Hesnawi et. al. (2017) affirmed that if 
the value of the Freundlich constant was such that $0.1<1 / \mathrm{n}<1$, adsorption was considered favorable, for both studies it was determined that the adsorption was favorable, but there are significant differences between the numerical values of $1 / \mathrm{n}_{\mathrm{F}}$ in both studies. Taamneh and Sharadqah (2017) and Ksakas et. al. (2018) found that the values of the constant $1 / \mathrm{n}_{\mathrm{F}}$ of the Freundlich model and the one observed in this investigation are in the same range but the value of the constant $\mathrm{K}_{\mathrm{F}}$ presents very different values among the aforementioned investigations. Erdem et. al. (2004) expressed that if the value of the Freundlich constant $n_{F}$ was between 2 and 10, good adsorption was shown, in this investigation the value of said constant was 2.85 , which can be said to be a good adsorption. The value of the Freundlich constant $\mathrm{K}_{\mathrm{F}}$, in this research and in Erdem, et. al. (2004) do not present significant differences.

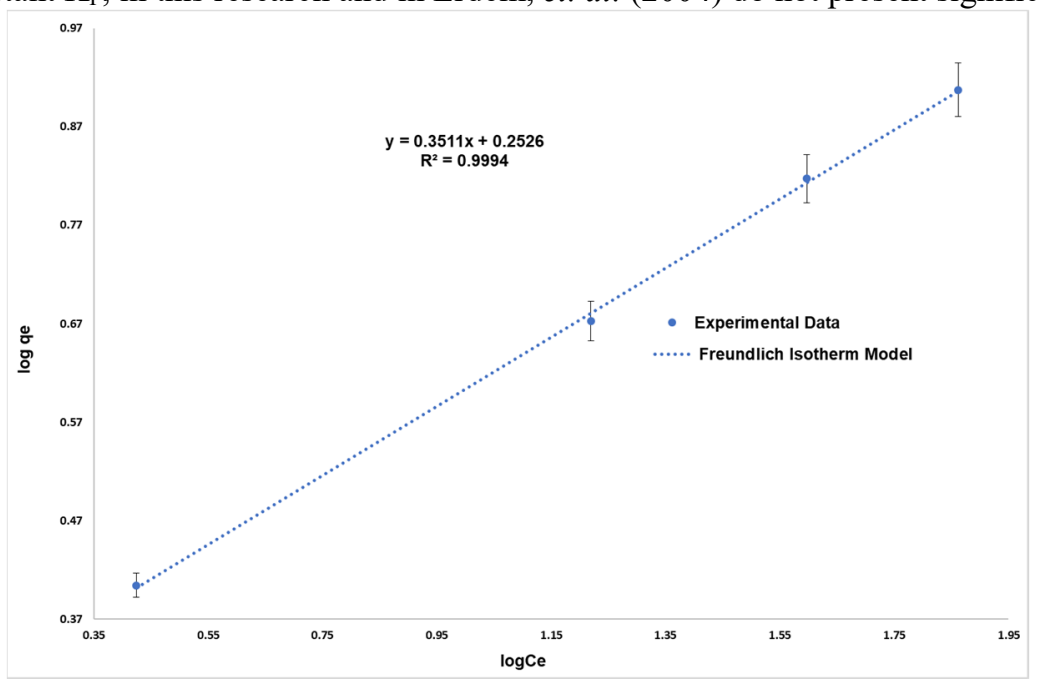

Figure 6. Freundlich Isotherm Model for $\mathrm{Cu}(\mathrm{II})$ onto Zeolite

\subsubsection{Temkin isotherm}

The Temkin isotherm model contains a factor that explicitly considers the adsorption interactions between the species and the adsorbate. This model assumes that: (i) the adsorption heat of all the molecules in the layer decreases linearly with the coverage due to adsorbent-adsorbate interactions, and (ii) the adsorption is characterized by a uniform distribution of the binding energies, up to maximum binding energy (Demiral \& Güngör, 2016; Kankrej et al., 2017; Subramani \& Thinakaran, 2017; Zhang et al., 2018). The Temkin isotherm model is presented in linear form with the following equation:

$$
q e=B \ln \left(K_{T} C e\right)
$$

Where: $\mathrm{B}=\mathrm{RT} / \mathrm{b}_{\mathrm{T}}, \mathrm{K}_{\mathrm{T}}$ is the Temkin Binding Equilibrium Constant $\left(\mathrm{L} \mathrm{mg}^{-1}\right), \mathrm{R}$ is the universal gas constant $\left(8.314 \times 10^{-3} \mathrm{KJ} \mathrm{mol}^{-1}{ }^{\circ} \mathrm{K}^{-1}\right), \mathrm{T}$ is the absolute temperature ${ }^{\circ} \mathrm{K}, \mathrm{b}_{\mathrm{T}}$ is the constant of the isotherm, which is related to the adsorption heat and $\mathrm{B}$ gives the adsorption heat $\left(\mathrm{J} \mathrm{mol}^{-1}\right)$.

The Temkin isotherm model is presented in linear form with the following equation:

$$
q e=B \ln K_{T}+B \ln C e
$$

To obtain the constants $\mathrm{B}$ and $\mathrm{K}_{\mathrm{T}}$ that are defined by the slope and the intercept respectively of the straight line of graphing qe in the ordinates and abscissas Ln Ce. Figure 7 shows the graph for the Temkin model. The value of $\mathrm{R}^{2}$ is high, although not comparable with other models and the values of \%ARE and $\chi^{2}$ (Table 1) are high, so the correlation between the experimental and calculated data is not very convenient. 


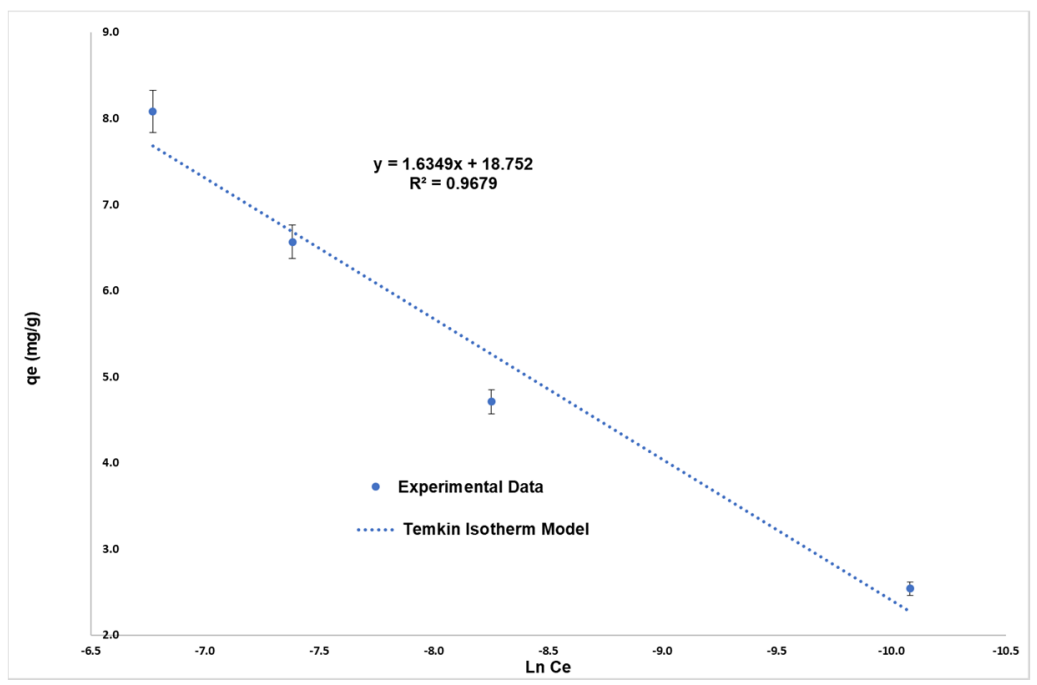

Figure 7. Temkin Isotherm Model for $\mathrm{Cu}$ (II) onto Zeolite

3.3.5 Dubinin-Radushkevich isotherm (D-R)

The model of the Dubinin-Radushkevich isotherm (D-R) is widely used to describe the adsorption process. This model does not assume a homogeneous surface or a constant adsorption potential. The linear form of this isotherm is expressed with the following equation:

$$
q e=q_{s} e^{-\beta_{D-R} \varepsilon^{2}}
$$

Where: qe is the quantity of ions sorbed in mol per gram of zeolite $\left(\mathrm{mol} \mathrm{g}^{-1}\right)$, qs is the saturation capacity of the isotherm $\left(\mathrm{mol} \mathrm{g}^{-1}\right), \beta_{\mathrm{D}-\mathrm{R}}$ is the Dubinin-Radushkevich constant $\left(\mathrm{mol}^{2}{ }^{0} \mathrm{~K}^{-1} \mathrm{~J}^{-2}\right)$ and $\varepsilon$ is correlated with the following expression:

$$
\varepsilon=R T \ln \left(1+\frac{1}{C e}\right)
$$

Where: $\varepsilon$ is the potential of Polanyi, and Ce is the concentration in equilibrium (mol L-1) (Kankrej et al., 2017; Zhang et al., 2018).

The linear form of this isotherm is expressed with the following equation:

$$
q e=\ln q_{s}-\beta_{D-R} \varepsilon^{2}
$$

The constants of the isotherm qs and $\beta_{\mathrm{D}-\mathrm{R}}$ are obtained from the intercept and the slope, respectively, of plotting the ordinates Ln qe and the abscissas $\varepsilon^{2}$. The constant $\beta_{\mathrm{D}-\mathrm{R}}$ is related to the mean of the free energy, E, which is the adsorption per molecule of the sorbate when it is transferred to the surface of the solid from infinity in the solution and can be calculated using the following relationship (Kankrej et al., 2017):

$$
E=\frac{1}{\sqrt{-2} \beta_{D-R}}
$$

The magnitude of $\mathrm{E}$ is used to estimate the type of adsorption process. The adsorption process is a chemical ion exchange if the magnitude of $E$ is between 8 and $16 \mathrm{KJ} \mathrm{mol}^{-1}$. If the value of $E$ is greater than $16 \mathrm{KJ} \mathrm{mol}^{-1}$ it is mainly a diffusion. In turn, when the magnitude of $\mathrm{E}$ is less than $8 \mathrm{KJ} \mathrm{mol}^{-1}$, the type of adsorption can be defined as a physical process (Demiral \& Güngör, 2016; Kaveeshwar et al., 2018; Rajabi et al., 2016). Figure 8 shows the graph for the Dubinin-Radushkevich model. $\mathrm{R}^{2}, \% \mathrm{ARE}$ and $\chi^{2}$ presented adequate values, but below other models. The value of $\mathrm{E}$ (Table 1) indicates that the adsorption process is of the chemical ion exchange type. In our results the Dubinin-Radushkevich model (D-R) was used, calculating the potential of adsorption E, the values obtained in this study and in Erdem et. al. (2004) were equal and indicate that the mechanism of adsorption is by ion exchange. Ksakas et. al. (2018) used this isotherm model, observing results very close to zero, very different results than previously expressed. 


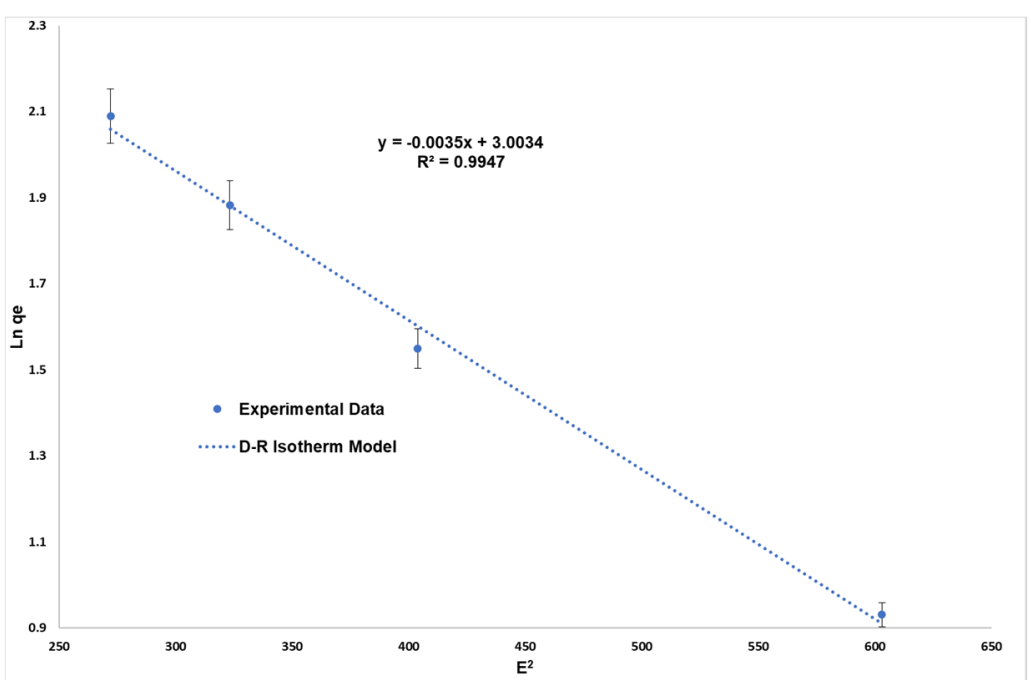

Figure 8. Dubinin-Radushkevich (D-R) Isotherm Model for Cu (II) onto Zeolite

\subsubsection{Redlich-Peterson Isotherm (R-P)}

This model is a combination of the Langmuir and Freundlich isotherms. It is used to describe the adsorption on both homogeneous and heterogeneous surfaces. It is considered as a comparison between these 2 models (Benzaoui, Selatnia, \& Djabali, 2017). This isotherm is expressed with the following equation:

$$
q e=\frac{K_{R P} C e}{\left(1+\alpha_{R P} C_{e}^{\beta_{R P}}\right)}
$$

Where: $K_{R P}$ is one Redlich-Paterson constant $\left(\mathrm{L} \mathrm{g} \mathrm{g}^{-1}\right)$, $\alpha_{R P}$ is another Redlich-Paterson constant $\left(\mathrm{L} \mathrm{mg}^{-1}\right), \beta_{R P}$ is the Redlich-Paterson exponent (dimensionless).

The values of $\beta_{R P}$ fluctuate between 0 and 1 . At low concentrations, the Redlich-Paterson isotherm approximates Henry's law (F. C. Wu, Liu, Wu, \& Tseng, 2010). When the constant $\beta_{R P}$ is very close to 1 , it is the same as the Langmuir equation and in high concentrations its behavior approaches that of the Freundlich isotherm, since the $\beta_{\mathrm{RP}}$ exponent tends to zero (Foo \& Hameed, 2010; Sogut \& Caliskan, 2017). From the transformation of the original equation, 2 linear forms are obtained. One of the linear forms of this isotherm is expressed with the following equation:

$$
\log \left[\left(K_{R P} \frac{C e}{q e}\right)-1\right]=\beta_{R P} \log C e+\log \left(\alpha_{R P}\right)
$$

The values of $\alpha_{R P}$ and $\beta_{R P}$ for the above equation can be determined from the intercept and the slope respectively of the straight line of plotting $\log \left[\left(\mathrm{K}_{\mathrm{RP}} \mathrm{C}_{\mathrm{e}} / \mathrm{q}_{\mathrm{e}}\right.\right.$ )-1] versus $\log \mathrm{C}_{\mathrm{e}}$ (Shahul Hameed, Muthirulan, \& Meenakshi Sundaram, 2017). Several values of the constants must be tested before obtaining the optimal line, in order to obtain the values of these constants. The range of values of these constants is very wide, ranging from 0.01 to several hundred, so it is not easy to obtain the correct values (F. C. Wu et al., 2010).

Another linear form of this equation is:

$$
\frac{c e}{q e}=\frac{1}{K_{R P}}+\frac{\alpha_{R P}}{K_{R P}} C_{e}^{\beta_{R P}}
$$

The constants of the Redlich-Paterson isotherm can be determined from graphing between $\mathrm{C}_{\mathrm{e}} / \mathrm{q}_{\mathrm{e}}$ versus $\mathrm{C}_{\mathrm{e}}{ }_{\mathrm{RP}}$. However, its application is very complex since it includes 3 unknown parameters $\alpha_{R P}, K_{R P}$ and $\beta_{R P}$. Therefore, a minimization procedure is adopted to obtain the maximum value of the coefficient of determination $\mathrm{R}^{2}$, between the theoretical data for qe obtained from the linearized form of the Redlich-Peterson Isotherm equation and the experimental data (Benzaoui et al., 2017). By trial and error, values of $\beta$ are adopted to obtain an optimal line. In the specific range, the values of $\beta$ are limited and it is easy to obtain the correct value (F. C. Wu et al., 2010). Figure 9 shows the performance of Redlich-Peterson Isotherm model. Using Microsoft Excel, a mathematical algorithm was used to maximize the value of $\mathrm{R}^{2}$, obtaining a maximum value of 0.99978 with a value of the coefficient $\beta_{\mathrm{RP}}=0.651$, this value explains the deviation of the Langmuir model, since when this value approaches 1 it is the same as the Langmuir model. The values of $\% A R E$ and $\chi^{2}$ (Table 1) are adequate. The use of this model validates what was obtained by the Freundlich model. The ratio of $\mathrm{K}_{\mathrm{R}} / \alpha \mathrm{R}$ indicates the adsorption capacity of the monolayer (Kaveeshwar et al., 2018), in this case it is much lower (1.82 $\mathrm{mg} \mathrm{Cu} \mathrm{g}^{-1}$ Zeolite) than that obtained by the Langmuir model $\left(9.08 \mathrm{mg} \mathrm{g}^{-1}\right)$ which corroborates for that the type of adsorption Freundlich is the best suited. 


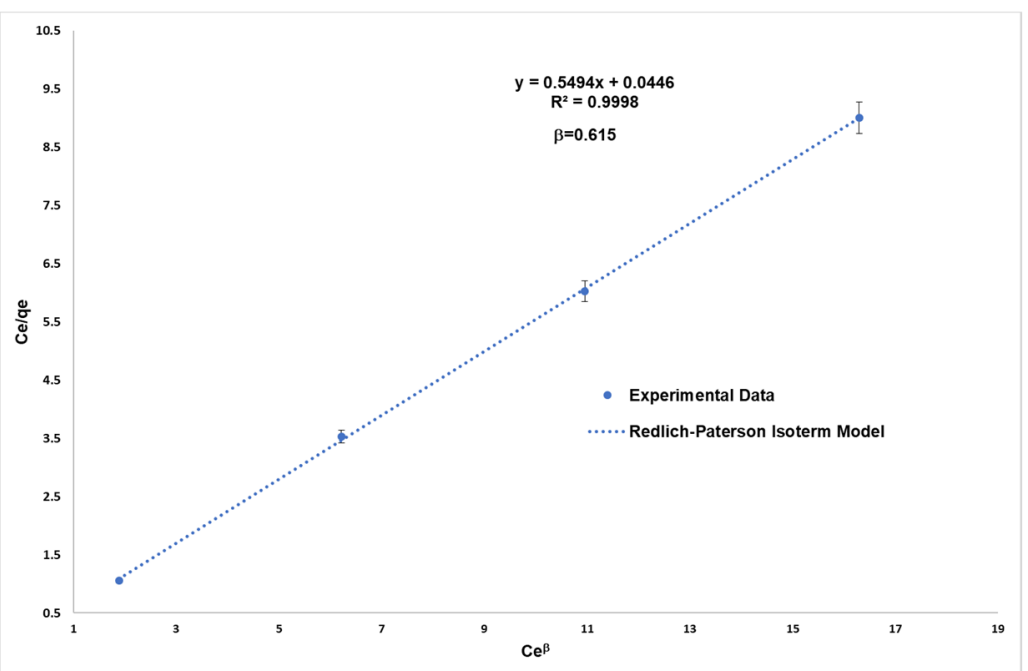

\subsubsection{Sips Isotherm}

Figure 9. Redlich-Paterson Isotherm Model for $\mathrm{Cu}(\mathrm{II})$ onto Zeolite

The Sips isotherm is a combined form of Langmuir and Freundlich isotherms applied for the prediction of heterogeneous adsorption systems. The Sips model avoids the inconveniences and limitations of the Langmuir or Freundlich models. At low concentrations, the adsorbate becomes Freundlich's isotherm and, therefore, does not obey Henry's law (Vijayaraghavan, Padmesh, Palanivelu, \& Velan, 2006). At high concentrations the Sips isotherm is reduced to the Langmuir isotherm (Dlugosz \& Banach, 2018). The equation of the Sips isotherm is characterized by containing a dimensionless heterogeneity factor, $\beta \mathrm{s}$. If $\beta \mathrm{s}=1$, the Sips equation is reduced to the Langmuir equation, which indicates that the adsorption process is homogeneous. The constant of isotherms of Sips $(\beta s)$ confirms whether the surface of the adsorbent is of heterogeneous nature or not (Sogut \& Caliskan, 2017). The Sips isotherm is expressed with the following equation:

$$
q e=\frac{K_{S} C_{e}^{\beta s}}{1+a s C_{e}^{\beta s}}
$$

Where: Ks is the equilibrium constant of the Sips isotherm $\left(\mathrm{L} \mathrm{mg}^{-1}\right)$, as is the maximum adsorption capacity (mg $\mathrm{g}^{-1}$ ) and $\beta \mathrm{s}$ is the model exponent (dimensionless).

The linear form of the Sips isotherm is:

$$
\ln (q e)=\beta s \ln (C e)+\ln \left(K_{S}-\text { asqe }\right)
$$

The coefficients of the Sips isotherm are calculated plotting $\ln (\mathrm{qe})$ versus $\ln (\mathrm{Ce})$, where $\beta$ s is the slope (Dlugosz \& Banach, 2018; Foo \& Hameed, 2010; Vijayaraghavan et al., 2006).

A rearrangement of the Sips equation can be expressed as follows:

$$
q e=\frac{a s K_{S} C_{e}^{\beta s}}{1+K_{S} C_{e}^{\beta s}},
$$

It should be plotted $\ln (\mathrm{Ce})$ versus $\ln (\mathrm{qe})$ and the inverse of the slope will be $\beta$ s and the inverse Ln of the intercept will represent Ks (Hamdaoui \& Naffrechoux, 2007b; Kaveeshwar et al., 2018; Sogut \& Caliskan, 2017).

Another linear form of this isotherm is expressed as follows:

$$
\beta s \ln (C e)=-\ln \left(\frac{K_{S}}{q e}\right)+\ln (a s)
$$

The coefficients of the equation may be calculated graphing $\operatorname{Ln}\left(\mathrm{K}_{\mathrm{s}} / \mathrm{q}_{\mathrm{e}}\right)$ versus $\operatorname{Ln}(\mathrm{Ce})$ (Foo \& Hameed, 2010). Figure 10 shows the performance of this model. Table 1 shows the results of $\mathrm{R}^{2}, \%$ ARE and $\chi^{2}$ which are very good. For this model, the exponent $\beta s$ is numerically the same as the exponent $\mathrm{n}$ of the Freundlich model, in the same way the numerical values of the constants of Freundlich and Sips are equal, with which the heterogeneous adsorption is corroborated. Wang et. al. (2008) for its study used concentrations not higher than $50 \mathrm{mg} \mathrm{L}^{-1} \mathrm{Cu}(\mathrm{II})$, which can be considered low concentrations, and at low concentrations the Sips isotherm becomes the Freundlich model (Vijayaraghavan et. al., 2006), for this reason, the Freundlich coefficients $1 / \mathrm{n}$ obtained in the results of the present study are very similar to the coefficient $\mathrm{n}$ of the Sips model calculated by Wang, et. al. (2008). 


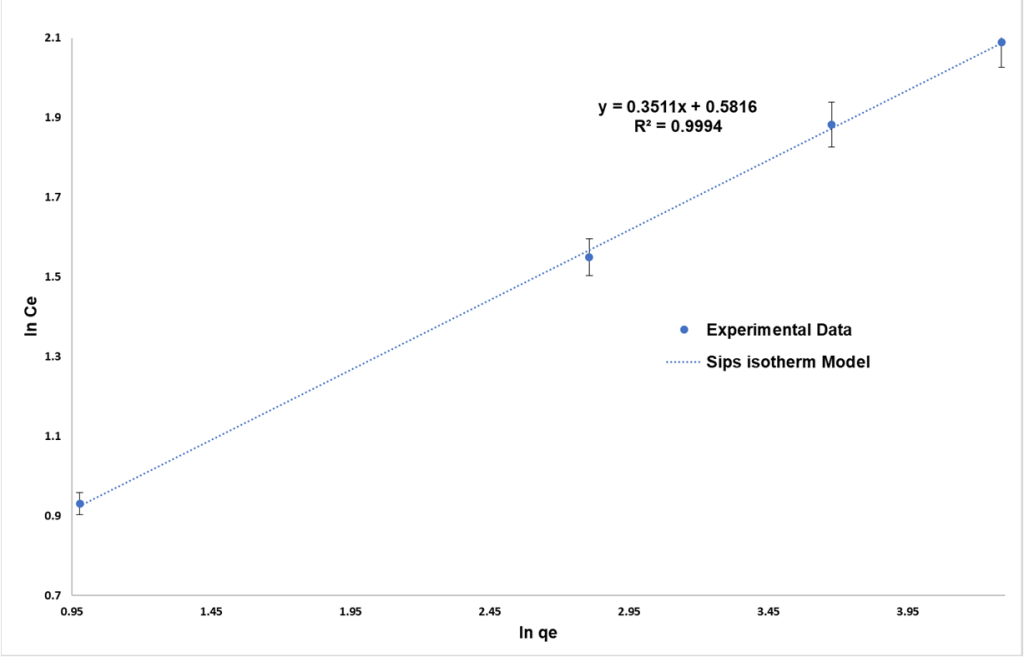

\subsubsection{Halsey Isotherm}

Figure 10. Sips Isotherm Model for $\mathrm{Cu}(\mathrm{II})$ onto Zeolite

The Halsey isotherm model is used to evaluate adsorption in a multilayer system where metal ions are located relatively far from the surface of the adsorbent. The model is expressed with the following equation:

$$
\ln (q e)=\left[\left(\frac{1}{n_{H}}\right) \ln \left(K_{H}\right)\right]-\frac{1}{n_{H}} \ln \frac{1}{c e}
$$

Where: $\mathrm{n}_{\mathrm{H}}$ is the constant of the equation and $\mathrm{K}_{\mathrm{H}}$ is the Halsey equilibrium constant.

The constants of the isotherm may be calculated graphing $\ln (\mathrm{qe})$ versus $\ln (1 / \mathrm{Ce})$ and from the straight line obtained, the slope is $n_{H}$ and the intercept represents $K_{H}$ (Kaveeshwar et al., 2018). Figure 11 illustrates the performance of this model. The values of $\mathrm{R}^{2}, \% \mathrm{ARE}$ and $\chi^{2}$ are excellent (Table 1), with which it may be affirmed that the adsorption of copper is in multilayers and the ions are relatively far from the surface.

3.3.9 Harkins-Jura isotherm

The Harkins-Jura model describes a multilayer adsorption and the existence of a heterogeneous distribution of the pores of the surface of the adsorbent. The model is defined with the following expression:

$$
\frac{1}{q_{e}^{2}}=\frac{B_{H J}}{A_{H J}}-\frac{1}{A_{H J}} \log (\mathrm{Ce})
$$

Where: $\mathrm{B}_{\mathrm{HJ}}$ is a model constant and $\mathrm{A}_{\mathrm{HJ}}$ is another model constant.

Graphing $1 / \mathrm{q}^{2}$ e versus $\log \left(\mathrm{C}_{\mathrm{e}}\right)$ the model constants are calculated with slope $\mathrm{A}_{\mathrm{HJ}}$ and intercept $\mathrm{B}_{\mathrm{HJ}}$ (Kaveeshwar et al., 2018). Figure 12 shows the performance of this model. Although the value of $\mathrm{R}^{2}$ is 0.94 , which indicates a high correlation, the values of $\%$ ARE and $\chi^{2}$ are very high (Table 1), indicating that there is no adequate correlation between the data obtained experimentally and those calculated with this model. Considering the results of the Halsey model and the $\mathrm{R}^{2}$ value of this model it is affirmed that the adsorption is in multilayers, but the pore distribution of the adsorbent is not heterogeneous.



Figure 11. Halsey Isotherm Model for $\mathrm{Cu}$ (II) onto Zeolite 


\subsubsection{Elovich isotherm}

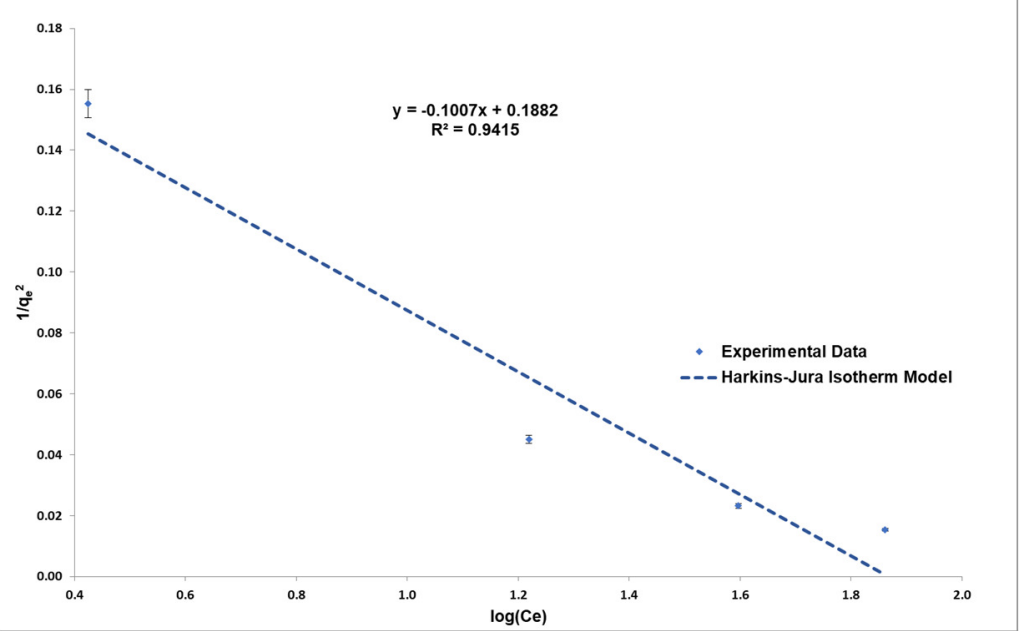

Figure 12. Harkins-Jura Isotherm Model for $\mathrm{Cu}(\mathrm{II})$ onto Zeolite

It assumes that the adsorption sites increase exponentially with adsorption, which implies a multilayer adsorption. Elovich model is expressed with the following equation:

The linear form is expressed:

$$
\frac{q e}{q m}=K_{E} C \exp \left(-\frac{q e}{q m}\right)
$$

$$
\ln \frac{q e}{C e}=-\frac{1}{q_{m}} q e+\ln K_{E} q_{m}
$$

Where: $\mathrm{q}_{\mathrm{m}}$ is the maximum adsorption capacity of Elovich (mg g-1) and $\mathrm{K}_{\mathrm{E}}$ is the equilibrium constant of Elovich $\left(\mathrm{L} \mathrm{mg}^{-1}\right)$.

$\mathrm{K}_{\mathrm{E}}$ and $\mathrm{q}_{\mathrm{m}}$ are calculated from the intercept and slope respectively of the straight line of $\ln (\mathrm{qe} / \mathrm{Ce})$ versus qe (Ayawei et al., 2017; Farouq \& Yousef, 2015; Kaveeshwar et al., 2018; Rangabhashiyam et al., 2014). Figure 13 illustrates the performance of this model. The value of $\mathrm{R}^{2}$ is convenient but the values of $\%$ ARE and $\chi^{2}$ are high (Table 1) discarding the suitability of this model. The maximum adsorption capacity of this model is well below that obtained by the Langmuir model.

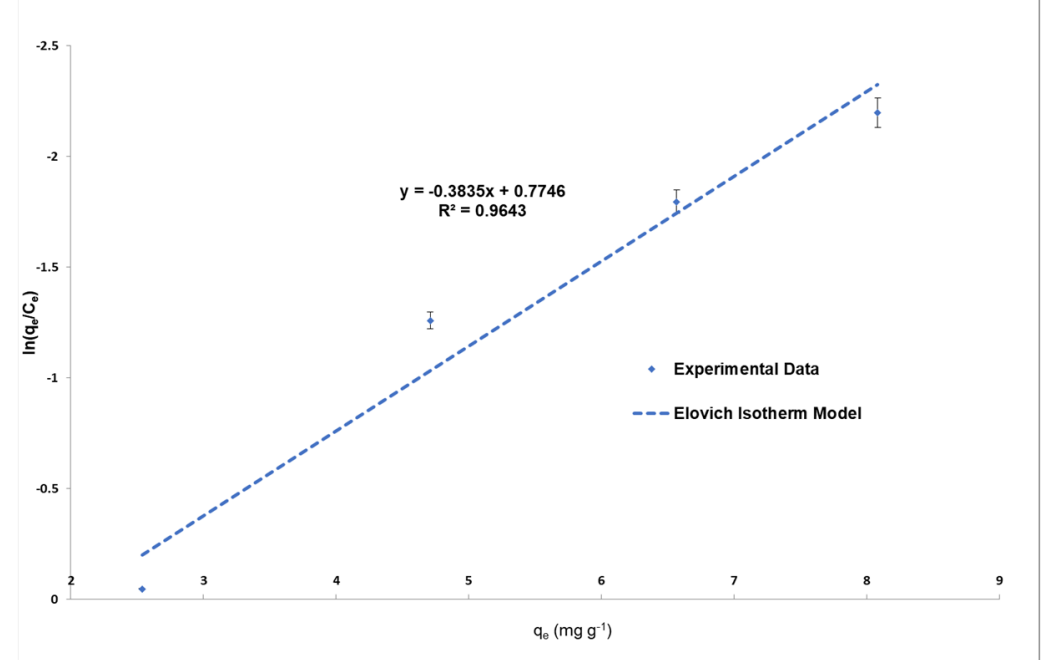

Figure 13. Elovich Isotherm Model for $\mathrm{Cu}(\mathrm{II})$ onto Zeolite

3.3.11 Flory-Huggins isotherm

This model emanates from the degree of coverage of the adsorbate on the adsorbent, expresses the degree of feasibility and spontaneity of the adsorption process. This model introduces a parameter that indicates the degree of coverage of the surface of the adsorbent, expressed with $\theta$. The general form is stated with the following equation:

$$
\frac{\theta}{C_{0}}=K_{F H}(1-\theta)^{n_{F H}}
$$

The linear form is expressed:

$$
\log \frac{\theta}{C_{0}}=\log K_{F H}+n_{F H} \log (1-\theta)
$$




$$
\theta=\left(1-\frac{C e}{C_{0}}\right)
$$

Where: $\mathrm{K}_{\mathrm{FH}}$ is the equilibrium constant of Flory-Huggins $\left(\mathrm{L} \mathrm{mg}^{-1}\right), \mathrm{n}_{\mathrm{FH}}$ is the exponent of the model and $\theta$ is the coverage parameter of the adsorbent surface.

The constant $\mathrm{K}_{\mathrm{FH}}$ can be used to calculate the spontaneity of Gibbs free energy (Rangabhashiyam et al., 2014). For its calculation is used the following equation (Foo \& Hameed, 2010):

$$
\Delta G^{0}=R T \ln K_{F H}
$$

For the calculation of the isotherm parameters, $\log \theta / C_{0}$ versus $\log (1-\theta)$ should be plotted, where the slope and the intercept represent $\mathrm{n}_{\mathrm{FH}}$ and $\mathrm{K}_{\mathrm{FH}}$ respectively. Figure 14 presents the graph for this model. This model expresses the degree of coverage of the adsorbate on the surface of the adsorbent, the coverage values $\theta$ range from 0.966 to 0.77 and these values vary inversely proportional to the initial concentration of the adsorbate. $\mathrm{n}_{\mathrm{FH}}$ is the number of adsorbates that are occupying the adsorption sites (Ayawei et al., 2017), therefore according to the results (Table 2) a limited number of adsorbates are found in the adsorption sites.



Figure 14. Flory-Huggins Isotherm Model for $\mathrm{Cu}(\mathrm{II})$ onto Zeolite

\begin{tabular}{|l|c|c|}
\hline \multicolumn{1}{|c|}{ MODEL } & \multicolumn{2}{|c|}{ Parameter } \\
\hline $\begin{array}{l}\text { Flory- } \\
\text { Huggins }\end{array}$ & $\mathrm{n}$ & 0.150 \\
\cline { 2 - 3 } & $\mathrm{K}_{\mathrm{FH}}$ & 7.940 \\
\cline { 2 - 3 } & $\mathrm{R}^{2}$ & 0.984 \\
\cline { 2 - 3 } & $\chi^{2}$ & 7.440 \\
\cline { 2 - 3 } Gugler- & $\% \mathrm{ARE}$ & 50.110 \\
\hline \multirow{4}{*}{ Javanovic } & $\mathrm{W}$ & -33430 \\
\cline { 2 - 3 } & $\mathrm{K}_{\mathrm{FG}}$ & $4.8{ }^{*} 10^{10}$ \\
\cline { 2 - 3 } & $\mathrm{R}^{2}$ & 0.948 \\
\cline { 2 - 3 } & $\chi^{2}$ & 2.300 \\
\cline { 2 - 3 } & $\% \mathrm{ARE}$ & 50.930 \\
\cline { 2 - 3 } & $\mathrm{q}_{\mathrm{m}}$ & 3.050 \\
\cline { 2 - 3 } & $\mathrm{KJ}_{\mathrm{J}}$ & 1.015 \\
\cline { 2 - 3 } & $\mathrm{R}^{2}$ & 0.833 \\
\cline { 2 - 3 } & $\chi^{2}$ & 2.220 \\
\cline { 2 - 3 } & $\% \mathrm{ARE}$ & 64.780 \\
\hline Kiselev & $\mathrm{K}_{\mathrm{n}}$ & -1.243 \\
\cline { 2 - 3 } & $\mathrm{K}_{\mathrm{i}}$ & -37.430 \\
\cline { 2 - 3 } & $\mathrm{R}^{2}$ & 0.604 \\
\cline { 2 - 3 } & $\chi^{2}$ & 4.160 \\
\cline { 2 - 3 } & $\% \mathrm{ARE}$ & 1344 \\
\hline
\end{tabular}

Table. 2. Isotherm model constants and correlation coefficients for $\mathrm{Cu}$ (II) adsorption onto Zeolite 3.3.12 Fowler-Guggenheim Isotherm

It is one of the simplest equations that consider the lateral interaction of the adsorbate molecules. Its general form is expressed below:

Its linear form is the following:

$$
K_{F G} C e=\frac{\theta}{1-\theta} \exp \left(\frac{2 \theta W}{R T}\right)
$$

$$
\ln \left[\frac{\operatorname{ce}(1-\theta)}{\theta}\right]=-\ln K_{F G}+\frac{2 W}{R T}
$$

Where: $\mathrm{K}_{\mathrm{FG}}$ is the equilibrium constant of Fowler-Guggenheim $\left(\mathrm{L} \mathrm{mg}^{-1}\right)$ and $\mathrm{W}$ is the energy of interaction 
between the molecules of the adsorbate $\left(\mathrm{KJ} \mathrm{mol}^{-1}\right)$ (Farouq \& Yousef, 2015; Hamdaoui \& Naffrechoux, 2007a).

The parameters of the equation are calculated by graphing $\ln \left[\mathrm{C}_{\mathrm{e}}(1-\theta) / \theta\right]$ versus $\theta$. From this straight line the intercept and the slope represent $\mathrm{K}_{\mathrm{FG}}$ and $\mathrm{W}$ respectively.

The charge and heat of adsorption vary linearly. When the values of $\mathrm{W}$ are greater than zero, it indicates that the interaction between the adsorbate molecules is attractive, but if the values of $\mathrm{W}$ are negative, the interaction is repulsive; if $\mathrm{W}=0$ there is no interaction (Farouq \& Yousef, 2015). As shown in Table 2, the value of W was 33,430 , indicating a repulsive interaction between the adsorbed molecules, and showing a decrease in the adsorption heat. The values of $\mathrm{R}^{2}$ are close to 0.95 , which shows a good correlation, but the suitability between the experimental data and those calculated with the model are not acceptable since the values of \%ARE and $\chi^{2}$ are very high. Figure 15 shows the performance of this model.



\subsubsection{Javanovic Isotherm}

Figure. 15. Fowler-Guggenheim Isotherm Model for $\mathrm{Cu}(\mathrm{II})$ onto Zeolite

This model assumes a superficial adsorption, it approximates to a localized adsorption on a monolayer, as expressed in the Langmuir model, but it is assumed that there is no lateral interaction between molecules. This model tolerates superficial vibrations of an adsorbed species (Farouq \& Yousef, 2015), allowing some mechanical contact between the adsorbate and the adsorbent (Ayawei et al., 2017). This model is expressed with the following equation (Farouq \& Yousef, 2015):

$$
q e=q_{m}\left(1-e^{K_{J} C e}\right)
$$

Its linear form is (Ayawei et al., 2017):

$$
\ln q e=\ln q_{m}-K_{J} C e
$$

Where: $\mathrm{K}_{\mathrm{J}}$ is the equilibrium constant of Javanovic $\left(\mathrm{L} \mathrm{mg}^{-1}\right)$.

When plotting lnqe versus $C e$, the slope and the intercept are $\mathrm{K}_{\mathrm{J}}$ and $\mathrm{qm}$ respectively. Figure $\mathbf{1 6}$ shows the performance of this model. The value of $\mathrm{R}^{2}$ is low compared to the other models studied and the values of \%ARE and $\chi^{2}$ are high (Table 2). The results indicate that adsorption by a monolayer was not feasible.

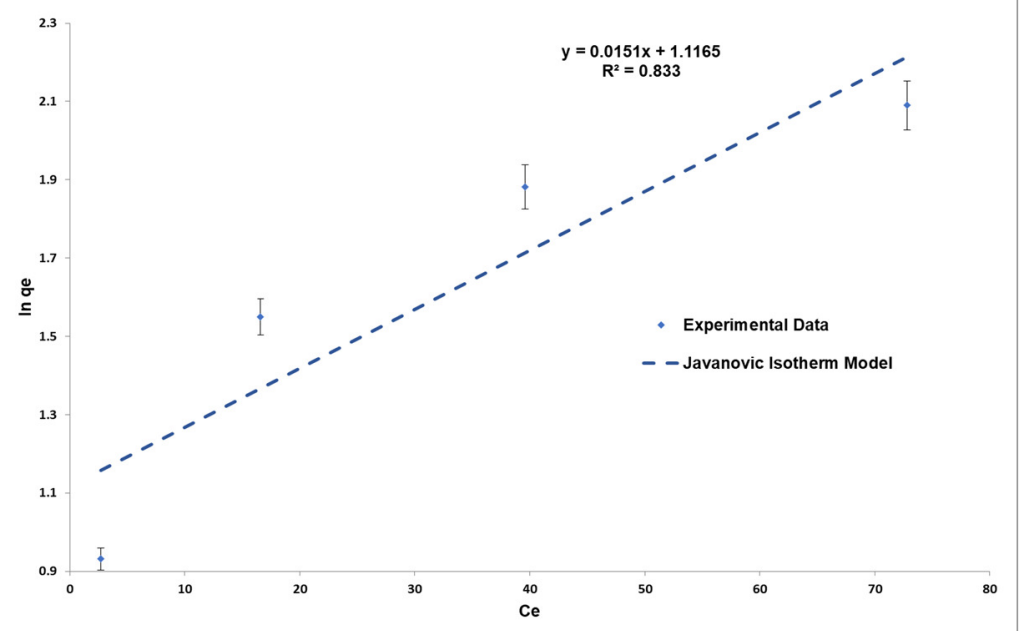

Figure 16. Javanovic Isotherm Model for $\mathrm{Cu}(\mathrm{II})$ onto Zeolite 


\subsubsection{Kiselev Isotherm}

This model is known as the model of the localized monomolecular layer and is only valid when $\theta \geq 0.68$. Its linear expression is:

$$
\frac{1}{\operatorname{Ce} *(1-\theta)}=K_{i} \frac{1}{\theta}+K_{i} K_{n}
$$

Where: $\mathrm{K}_{\mathrm{i}}$ is Kiselev constant $\left(\mathrm{L} \mathrm{mg}^{-1}\right)$ and $\mathrm{K}_{\mathrm{n}}$ is the equilibrium constant of complex formation between the molecules of the adsorbate.

Constants are calculated by plotting $1 /[\mathrm{Ce} *(1-\theta)]$ versus $1 / \theta$ where the slope and the intercept represent $\mathrm{Ki}$ and $\mathrm{K}_{\mathrm{i}}{ }^{*} \mathrm{Kn}$ respectively (Ayawei et al., 2017). Figure 17 illustrates the performance of this model. The use of this model is valid since the lower value of $\theta$ was 0.77 but the values of $\mathrm{R}^{2}, \%$ ARE and $\chi^{2}$ (Table 2) are unacceptable. This model does not describe in any way the behavior of the adsorption for this study.

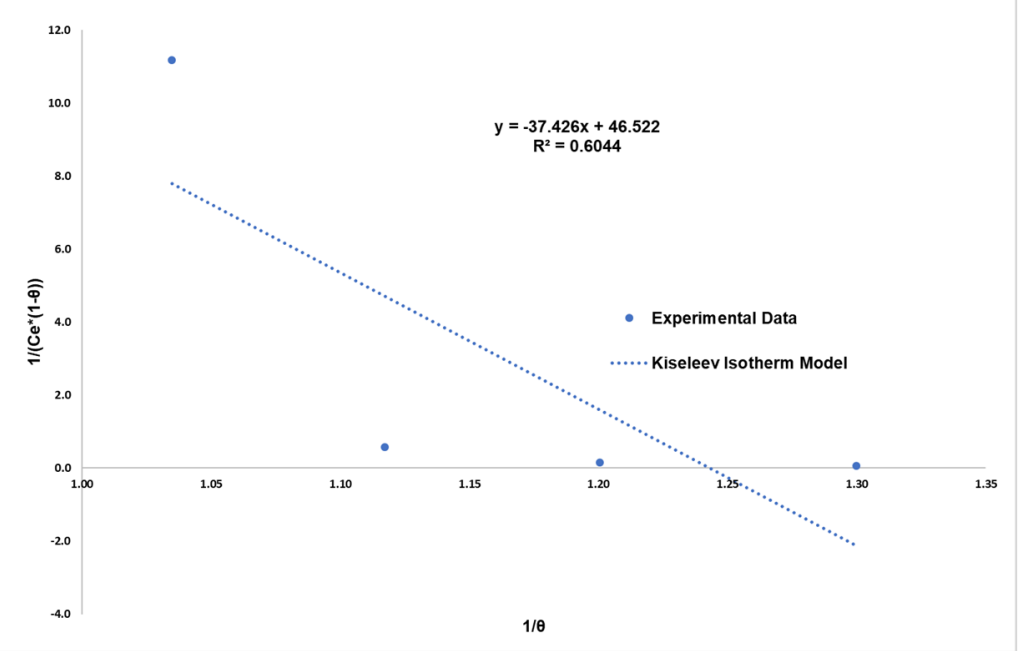

Figure 17. Kiselev Isotherm Model for Cu(II) onto Zeolite

\subsection{Isotherms, and Maximum Adsorption Capacity}

Merrikhpour and Jalali (2012) (Merrikhpour \& Jalali, 2013) made a summary of previous studies on the adsorption of copper by Zeolites and found that this was in the range of 0.69 to $12.7 \mathrm{mg} \mathrm{Cu}$ (II) $\mathrm{g}^{-1}$ Zeolite; in this study it was

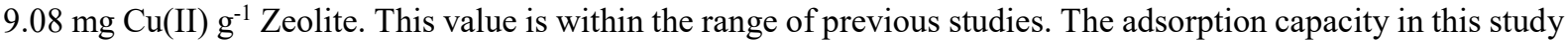
was superior to that reported in studies reviewed by the aforementioned authors. Hesnawi et. al. (2017) (Hesnawi, R. Jamal, F. Eswayah, A. Maga, 2017) found that the maximum adsorption capacity obtained by means of the Langmuir model for copper was $1.08 \mathrm{mg} \mathrm{g}^{-1}$ of zeolite, being very low compared to that obtained in this study, but Taamneh and Sharadqah (2017) reported a value of $14.3 \mathrm{mg} \mathrm{Cu}(\mathrm{II}) \mathrm{g}^{-1}$ of zeolite, this being the highest value reported. Atkovska et. al. (2018) (Atkovska, Lisichkov, Ruseska, Dimitrov, \& Grozdanov, 2018) made a summary of several studies of the removal of copper by natural zeolites and concluded that these removed $75 \%$ of this metal, which is low in comparison with what was found in this study since the maximum adsorption stood at $96.15 \%$.

In the present study it was observed that increasing the temperature increased the adsorption of copper, which is consistent with what was observed by Panayotova (2001). The effect of temperature is a significant physicalchemical parameter, since temperature can change the capacity of adsorption. If the capacity of adsorption increases with increasing temperature, the adsorption process is endothermic (Al-Degs et al., 2008b; Santos et al., 2017; Yagub, Sen, Afroze, \& Ang, 2014). This may be due to the increased mobility of the adsorbate molecules and a possible increase in the number of exchange sites (Malamis \& Katsou, 2013; Yagub et al., 2014).

The adsorption isotherms show how the adsorbate interacts with the adsorbent and how equilibrium is reached. According to the models used in this study it can be concluded that the interaction between adsorbent and adsorbate does not exhibit a linear behavior, as expressed with Henry's model, since experimental data with this model do not have good correlation. The adsorption surface is not homogeneous and the sorption process is not performed in a monolayer, as formulated in the Langmuir model; but it can be expressed as a heterogeneous process with an exponential distribution of its active sites and their adsorption energies, as demonstrated with the Freundlich model. The results obtained with the Freundlich model validate the non-linearity observed with the Henry's model, since the Freundlich model also shows a lack of linearity and this model was the one that presented the best correlation $\left(\mathrm{R}^{2}=0.999\right)$ of all the models used in this study. The Freundlich model explains in an excellent way the process observed in the laboratory tests. The Temkin constant, bT, which is related to the heat of sorption, presented low values (lower than $8 \mathrm{KJ} \mathrm{mol}^{-1)}$ which indicates a weak interaction between the adsorbent and the adsorbate, which suggests an ion exchange sorption process. The results achieved with the Dubinin-Radushkevich model confirm and validate what was derived of the Temkin constant, namely that an ion exchange was performed, since the 
magnitude of the constant E derived from the Dubinin-Radushkevich model also indicate an ion exchange. The results obtained from the Redlich-Peterson model confirm that the data fit better to what is mentioned in the Freundlich model, more than what was observed in the Langmuir model. With the use of the coefficient of the Redlich-Peterson model it was found that the calculation of the Freundlich coefficient was adequate, since according to the relationship $\left(1-\beta_{\mathrm{RP}}\right)=1 / \mathrm{nF}$, the experimental results were validated, and the results obtained in both exponents are significantly the same. In order to confirm a heterogeneous adsorption shown with the Freundlich model, the Sips model was used, showing a perfect analogy between the Sips coefficient $\left(\beta_{\mathrm{s}}\right)$ and the Freundlich model exponent, with which the heterogeneous sorption process is validated. The Halsey model presents a good correlation $(\mathrm{R} 2=0.999)$ with the values obtained experimentally, which suggests that the adsorbent material has a heterogeneous nature in its pores and its active sites, in addition to a multilayer adsorption. With the Harkin-Jura model a good correlation $\left(\mathrm{R}^{2}=0.94\right)$ with the experimental data was observed; therefore, the existence of a multilayer adsorption and of a pore distribution on the surface of the heterogeneous adsorbent is suggested. With the use of the Elovich model, the multilayer adsorption is reaffirmed, taking into account that the experimental data present a good correlation $\left(\mathrm{R}^{2}=0.96\right)$. With the use of the last three mentioned models it can be concluded that the adsorption process is carried out in multilayer, with a heterogeneous distribution. The Flory-Huggins model was used in order to know the characteristic degree of surface coverage of the adsorbent by the adsorbate. The processes of general coverage indicate that $15 \%$ of the binding sites on the surface of the adsorbent were covered by metal ions during the sorption process. The Fowler-Guggenheim model was selected to determine what type of lateral interaction between the adsorbate molecules would be manifested. According to the results of this model, it follows that there is a lateral repulsion between the molecules of the adsorbate. The model Javanovic had a poor fit to the experimental data, therefore, the assumptions made in this model are discarded, and an approximation to a localized sorption in a monolayer is not feasible, which again validate the experimental observations in the Freundlich model of a heterogeneous sorption. This model also expresses that there is no interaction between molecules, which is discarded and confirms the interaction expressed in the Fowler-Guggenheim model. The Kiselev model clearly shows a very low correlation with the experimental data, whereby a sorption is discarded by means of a localized monomolecular layer.

\subsection{Numerical simulations in porous media}

3.5.1 Model of Transport in Porous Medium

The conventional model of the transport process is based on the advection-dispersion equation:

$$
\frac{\partial c}{\partial t}=\nabla \cdot(D \cdot \nabla c)-\nabla \cdot(v c)
$$

Where: $\mathrm{t}$ is time, $\mathrm{c}$ is concentration, $\mathrm{D}$ tensor of the dispersion coefficient and $\mathrm{v}$ speed vector (Auset \& Keller, 2004; Sahimi, 2011; Zheng \& Bennett, 2002).

The general transport model incorporates 3 processes:

- Advection. Driven by the flow of the liquid.

- Dispersion. Caused by the heterogeneity of the material.

- Adsorption. The main parameter is the adsorption coefficient $\mathrm{K}_{\mathrm{D}}$ (Zheng \& Bennett, 2002)

$$
\left(1+\frac{K_{D} \rho}{\eta}\right) \frac{\partial c}{\partial t}=-v \frac{\partial c}{\partial x}+D \frac{\partial_{c}^{2}}{\partial_{x}^{2}}
$$

Where: $K_{D}$ is the adsorption coefficient (length ${ }^{3}$ mass $^{-1}$ ), $\rho$ is the density (mass length ${ }^{-3}$ ), $\eta$ porosity of the material (dimensionless), c concentration (mass length ${ }^{-3}$ ), $\mathrm{t}$ time (time), $v$ fluid velocity (length time ${ }^{-1}$ ), $\mathrm{x}$ distance (length), and D Diffusivity coefficient (length ${ }^{2}$ time $^{-1}$ ).

The first term of equation (51) refers to the adsorption and this can be replaced by:

$$
\frac{\rho(1-\eta)}{\eta} \frac{\partial q}{\partial t}
$$

A rearrangement of the terms the equation is expressed:

$$
\frac{\partial c}{\partial t}=-v \frac{\partial c}{\partial t}+D \frac{\partial_{c}^{2}}{\partial_{x}^{2}}-\frac{\rho(1-\eta)}{\eta} \frac{\partial q}{\partial t}
$$

Where:

$\frac{\partial c}{\partial t}$ is the rate of change in the concentration of the solute in the liquid phase,

$v \frac{\partial c}{\partial t}$ is the term of the advective flow,

$D \frac{\partial_{c}^{2}}{\partial_{x}^{2}}$ is the transport of solute by dispersion, and

$\frac{\rho(1-\eta)}{\eta} \frac{\partial q}{\partial t}$ is the rate of solute adsorbed by the solid phase (Basavaraju Agasanapur, 2008).

When making a substitution:

$$
\frac{\partial q}{\partial t}=\frac{\partial q}{\partial c}\left[\frac{\partial c}{\partial t}\right]
$$

Using the isotherm model proposed by Freundlich, the model is expressed with the following equation:

$$
\frac{\partial c}{\partial t}=-v \frac{\partial c}{\partial x}+D \frac{\partial_{c}^{2}}{\partial_{x}^{2}}-\left[1-\frac{\rho K_{F} n_{F}}{\eta} c\left(1-n_{F}\right)\right]
$$

The equation given in (57) represents the Advective Dispersion Reaction Equation (ADRE) coupled with Freundlich adsorption isotherm. 


\subsubsection{Simulation software}

A simulation was carried out through the software COMSOL Multiphysics ${ }^{\circledR}$. COMSOL is a software package to solve and analyze finite element, especially coupled to physical or multiphysics phenomena. It includes a complete environment to model almost any physical phenomenon that can be described using ordinary differential equations (ODE's) and partial differential equations (PDE's) (COMSOL Incorporated, 2015).

\subsubsection{Parameter}

For this problem a cylindrical column with a diameter of $1 \mathrm{~m}$ with a height $(\mathrm{Z})$ of $10 \mathrm{~m}$ was used. This column was packed with the zeolitic material. Acid drainage with $50 \mathrm{mg} \mathrm{L}^{-1}$ of CU(II) was fed from the bottom at a constant speed of $0.001 \mathrm{~m} \mathrm{seg}^{-1}$. The porosity of the material was measured by means of the liquid displacement technique using an Ohaus ${ }^{\circledR}$ Pioneer analytical balance. The porosity of the material was determined at 0.4242 and the density was measured by the weighing technique of a given volume with volumetric material and quantified in $915.27 \mathrm{Kg}$ $\mathrm{m}^{-3}$. The values of the constants $\left(\mathrm{K}_{\mathrm{F}}\right.$ and $\left.\mathrm{n}\right)$ of the isotherm for Freundlich calculated in this study were the ones that best adjusted to the experimental data and therefore the most recommended for its use, they were calculated according to what is stated in the subsection 3.2.3 and la Figure 5. Effective Diffusivity Coefficient was calculated according to the model of Millington and Quirk. The values used for Fluid Diffusion Coefficient and Dispersion Tensor were those provided in the COMSOL support material. Table 3 shows the parameters for simulation. The simulation was carried out assuming that the column was completely filled with a concentration solution of $50 \mathrm{mg}$ $\mathrm{L}^{-1}$ of $\mathrm{Cu}(\mathrm{II})$.

\begin{tabular}{|l|c|}
\hline Velocity $\left(\mathrm{m} \mathrm{seg}^{-1}\right)$ & 0.01 \\
\hline Porosity $(\varepsilon \mathrm{Q})$ & 0.42 \\
\hline Density $\left(\mathrm{Kg} \mathrm{m}^{-3}\right)$ & 980 \\
\hline $\begin{array}{l}\text { Fluid Diffusion Coeficient } \\
\left(\mathrm{m}^{2} \mathrm{seg}^{-1}\right)\end{array}$ & $1.00 \mathrm{E}-09$ \\
\hline $\begin{array}{l}\text { Effective Diffusivity } \\
\text { Coeficient: }\end{array}$ & \\
\hline Millington and Quirk Model & $\tau=\varepsilon \mathrm{Q}^{-1 / 3}$ \\
\hline Adsortion: & \\
\hline Freundlich & 0.1209 \\
\hline $\mathrm{K}_{\mathrm{F}}\left(\mathrm{mol} \mathrm{Kg}{ }^{-1}\right)$ & 0.3511 \\
\hline $\mathrm{n}$ (Dimensionless) & $8.70 \mathrm{E}-07$ \\
\hline Dispersion Tensor $\left(\mathrm{m}^{2} \mathrm{seg}^{-1}\right)$ & \\
\hline
\end{tabular}

Table 3. Parameters for Numerical Simulation

The following figure show the concentration of $\mathrm{Cu}(\mathrm{II})$ at a certain time at the exit of the column where the simulation was performed.

Time $=80 \mathrm{~min}$ Slice: Concentration $\left(\mathrm{mol} / \mathrm{m}^{3}\right)$

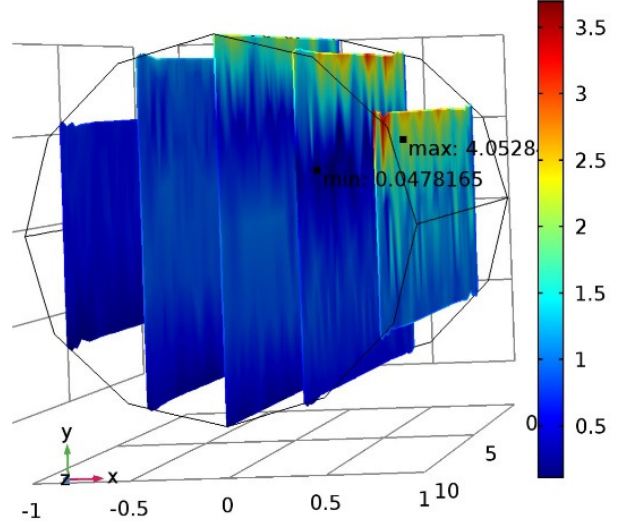

Figure 18. Simulations at time 80 minutes

\section{Conclusions}

The optimum $\mathrm{pH}$ value for the removal of copper is neutral. The sequence of the isotherms was: Freundlich $>$ R$\mathrm{P}>$ Sips $=$ Halsey $>$ D-R $>$ Flory-Huggins $>$ Langmuir $>$ Temkin $>$ Elovich $>$ Fowler-Guggenheim $>$ Henry's $>$ Kiselev. Copper removal is feasible through a Zeolite that was subjected to intense acid treatment. 


\section{Acknowledgement}

We are grateful to National Council for Science and Technology (CONACYT) for the support for the development of the project: Sustainable strategies for the mitigation of environmental impacts of mining activity in urban-rural areas, Proposals to remedy pollution (Project number 2016-01-4104), Faculty of Zootechnics and Ecology, Autonomous University of Chihuahua, Rafael Escobedo Bautista, Alfredo Campos Trujillo, Silvia Miranda Navarro, Karla Campos Venegas and to all the people who with their comments enriched this work

\section{References}

Abdel Salam, O. E., Reiad, N. A., \& ElShafei, M. M. (2011). A study of the removal characteristics of heavy metals from wastewater by low-cost adsorbents. Journal of Advanced Research, 2(4), $297-303$. https://doi.org/10.1016/j.jare.2011.01.008

Al-Degs, Y. S., El-Barghouthi, M. I., El-Sheikh, A. H., \& Walker, G. M. (2008a). Effect of solution pH, ionic strength, and temperature on adsorption behavior of reactive dyes on activated carbon. Dyes and Pigments, 77(1), 16-23. https://doi.org/10.1016/j.chemosphere.2011.02.032

Al-Degs, Y. S., El-Barghouthi, M. I., El-Sheikh, A. H., \& Walker, G. M. (2008b). Effect of solution pH, ionic strength, and temperature on adsorption behavior of reactive dyes on activated carbon. Dyes and Pigments, 77(1), 16-23. Retrieved from https:/www.sciencedirect.com/science/article/pii/S0304389408013770

Atkovska, K., Lisichkov, K., Ruseska, G., Dimitrov, A. T., \& Grozdanov, A. (2018). Removal of heavy metal ions from wastewater using conventional and nanosorbents: A review. Journal of Chemical Technology and Metallurgy, 53(2), 202-217. Retrieved from http://web.a.ebscohost.com/ehost/pdfviewer/pdfviewer?vid=0\&sid=b1f8277c-85a2-419b-80b65 fc0c06ac191\%40sessionmgr4010

Auset, M., \& Keller, A. A. (2004). Pore-scale processes that control dispersion of colloids in saturated porous media. Water Resources Research, 40(3), W03503. https://doi.org/10.1029/2003WR002800

Ayawei, N., Ebelegi, A. N., \& Wankasi, D. (2017). Modelling and Interpretation of Adsorption Isotherms. Journal of Chemistry, 2017. https://doi.org/10.1155/2017/3039817

Basavaraju Agasanapur. (2008). FEM Analysis of Contaminate Transport in loamy Desert. In COMSOL Conference 2008 Boston (p. 15).

Ben-Ali, S., Jaouali, I., Souissi-Najar, S., \& Ouederni, A. (2017). Characterization and adsorption capacity of raw pomegranate peel biosorbent for copper removal. Journal of Cleaner Production, 142, 3809-3821. https://doi.org/10.1016/j.jclepro.2016.10.081

Benzaoui, T., Selatnia, A., \& Djabali, D. (2017). Adsorption of copper (II) ions from aqueous solution using bottom ash of expired drugs incineration. Adsorption Science \& Technology, (Ii), 026361741668509. https://doi.org/10.1177/0263617416685099

Choi, H. J., Yu, S. W., \& Kim, K. H. (2016). Efficient use of Mg-modified zeolite in the treatment of aqueous solution contaminated with heavy metal toxic ions. Journal of the Taiwan Institute of Chemical Engineers, 63, 482-489. https://doi.org/10.1016/j.jtice.2016.03.005

Chutia, P., Kato, S., Kojima, T., \& Satokawa, S. (2009). Arsenic adsorption from aqueous solution on synthetic zeolites. Journal of Hazardous Materials, 162(1), 440-447. https://doi.org/10.1016/j.jhazmat.2008.05.061

COMSOL Incorporated. (2015). COMSOL Multiphysics.

Demiral, H., \& Güngör, C. (2016). Adsorption of copper(II) from aqueous solutions on activated carbon prepared from grape bagasse. Journal of Cleaner Production, 124, $103-113$. https://doi.org/10.1016/J.JCLEPRO.2016.02.084

Demirbas, A. (2009). Agricultural based activated carbons for the removal of dyes from aqueous solutions: A review. Journal of Hazardous Materials, 167(1-3), 1-9. https://doi.org/10.1016/j.jhazmat.2008.12.114

Dlugosz, O., \& Banach, M. (2018). Kinetic, isotherm and thermodynamic investigations of the adsorption of Ag + and $\mathrm{Cu} 2+$ on vermiculite. Journal of Molecular Liquids, 258, $295-309$. https://doi.org/10.1016/j.molliq.2018.03.041

Erdem, E., Karapinar, N., \& Donat, R. (2004). The removal of heavy metal cations by natural zeolites. Journal of Colloid and Interface Science, 280(2), 309-314. https://doi.org/10.1016/j.jcis.2004.08.028

Fardjaoui, N. E. H., El Berrichi, F. Z., \& Ayari, F. (2017). Kaolin-issued zeolite A as efficient adsorbent for Bezanyl Yellow and Nylomine Green anionic dyes. Microporous and Mesoporous Materials, 243, 91-101. https://doi.org/10.1016/j.micromeso.2017.01.008

Farouq, R., \& Yousef, N. S. (2015). Equilibrium and Kinetics Studies of adsorption of Copper (II) Ions on Natural Biosorbent. International Journal of Chemical Engineering and Applications, 6(5), 319-324. https://doi.org/10.7763/IJCEA.2015.V6.503

Fiol, N., \& Villaescusa, I. (2009). Determination of sorbent point zero charge: Usefulness in sorption studies. Environmental Chemistry Letters, 7(1), 79-84. https://doi.org/10.1007/s10311-008-0139-0

Foo, K. Y., \& Hameed, B. H. (2010). Insights into the modeling of adsorption isotherm systems. Chemical 
Engineering Journal, 156, 2-10. https://doi.org/10.1016/j.cej.2009.09.013

Ghasemi, M., Javadian, H., Ghasemi, N., Agarwal, S., \& Gupta, V. K. (2016). Microporous nanocrystalline NaA zeolite prepared by microwave assisted hydrothermal method and determination of kinetic, isotherm and thermodynamic parameters of the batch sorption of Ni (II). Journal of Molecular Liquids, 215, 161-169. https://doi.org/10.1016/j.molliq.2015.12.038

Gupta, V. K., Mittal, A., \& Mittal, J. (2012). RSC Advances Batch and bulk removal of hazardous colouring agent Rose Bengal by adsorption techniques using bottom ash as adsorbent. RSC Advances, 2, 8381-8389. https://doi.org/10.1039/c2ra21351f

Hamdaoui, O., \& Naffrechoux, E. (2007a). Modeling of adsorption isotherms of phenol and chlorophenols onto granular activated carbon. Part I. Two-parameter models and equations allowing determination of thermodynamic parameters. Journal of Hazardous Materials, 147(1-2), 381-394. https://doi.org/10.1016/j.jhazmat.2007.01.021

Hamdaoui, O., \& Naffrechoux, E. (2007b). Modeling of adsorption isotherms of phenol and chlorophenols onto granular activated carbon. Part II. Models with more than two parameters. Journal of Hazardous Materials, 147(1-2), 401-411. https://doi.org/10.1016/j.jhazmat.2007.01.023

Hesnawi, R. Jamal, F. Eswayah, A. Maga, R. E. (2017). Heavy Metal Removal from Aqueous Solution Using Natural Libyan Zeolite and Activated Carbon. Journal of Environmental Science, 1, 34-45. Retrieved from http://www.mayfeb.com/OJS/index.php/ENV/article/view/285/171

Hossain, M. a, Ngo, H. H., Guo, W. S., \& Nguyen, T. V. (2012). Biosorption of Cu (II) from water by banana peel based biosorbent: experiments and models ofadsorption and desorption. Journal of Water Sustainability, 2(1), 87-104. https://doi.org/10.11912/jws.2.1.87-104

Humelnicu, I., Băiceanu, A., Ignat, M. E., \& Dulman, V. (2017). The removal of Basic Blue 41 textile dye from aqueous solution by adsorption onto natural zeolitic tuff: Kinetics and thermodynamics. Process Safety and Environmental Protection, $\quad 105, \quad 274-287$. https://doi.org/https://doi.org/10.1016/j.psep.2016.11.01610.1016/j.psep.2016.11.016

Kalhori, E. M., Al-Musawi, T. J., Ghahramani, E., Kazemian, H., \& Zarrabi, M. (2017). Enhancement of the adsorption capacity of the light-weight expanded clay aggregate surface for the metronidazole antibiotic by coating with $\mathrm{MgO}$ nanoparticles: Studies on the kinetic, isotherm, and effects of environmental parameters. Chemosphere, 175, 8-20. https://doi.org/10.1016/j.chemosphere.2017.02.043

Kankrej, S. R., Kulkarni, M. S., \& Borhade, A. V. (2017). Adsorption Isotherms, Thermodynamics, Kinetics and Mechanism for the Removal of $\mathrm{Ca} 2+, \mathrm{Mg} 2+$ and $\mathrm{Cu} 2+$ Ions onto Nosean Prepared by using Coal Fly Ash. Journal of Environmental Chemical Engineering, 6(2), 2369-2381. https://doi.org/https://doi.org/10.1016/j.jece.2017.12.048

Kaveeshwar, A. R., Ponnusamy, S. K., Revellame, E. D., Gang, D. D., Zappi, M. E., \& Subramaniam, R. (2018). Pecan shell based activated carbon for removal of iron(II) from fracking wastewater: Adsorption kinetics, isotherm and thermodynamic studies. Process Safety and Environmental Protection, 114, 107-122. https://doi.org/https://doi.org/10.1016/j.psep.2017.12.007

Kim, N., Park, M., \& Park, D. (2015). A new efficient forest biowaste as biosorbent for removal of cationic heavy metals. Bioresource Technology, 175, 629-632. https://doi.org/10.1016/j.biortech.2014.10.092

Kocaoba, S., Orhan, Y., \& Akyüz, T. (2007). Kinetics and equilibrium studies of heavy metal ions removalby use of natural zeolite. Desalination, 214(1-3), 1-10. https://doi.org/10.1016/j.desal.2006.09.023

Ksakas, A., Tanji, K., El Bali, B., Taleb, M., \& Kherbeche, A. (2018). Removal of Cu (II) ions from aqueous solution by adsorption using natural clays: Kinetic and thermodynamic studies. Journal of Materials and Environmental Science, 9(3), 1075-1085. https://doi.org/10.26872/jmes.2017.9.3.119

Li, X., Zhou, H., Wu, W., Wei, S., Xu, Y., \& Kuang, Y. (2015). Studies of heavy metal ion adsorption on Chitosan/Sulfydryl-functionalized graphene oxide composites. Journal of Colloid and Interface Science, 448. https://doi.org/10.1016/j.jcis.2015.02.039

Lin, J., Zhan, Y., \& Zhu, Z. (2011). Adsorption characteristics of copper ( II ) ions from aqueous solution onto humic acid-immobilized surfactant-modified zeolite. Colloids and Surfaces A: Physicochemical and Engineering Aspects, 384(1-3), 9-16. https://doi.org/10.1016/j.colsurfa.2011.02.044

López-Aguilar, H. A., Huerta-Reynosoa, E. A., , J.A. Gómez, J. M. O.-R., Duarte-Moller, A., \& Pérez-Hernández, A. (2016). Life cycle assessment of regional brick manufacture. Materiales de Construcción, 66(322), 1-9. https://doi.org/https://doi.org/10.3989/mc.2016.02315

Ltaief, O. O., Siffert, S., Fourmentin, S., \& Benzina, M. (2015). Synthesis of Faujasite type zeolite from low grade Tunisian clay for the removal of heavy metals from aqueous waste by batch process: Kinetic and equilibrium study. Comptes Rendus $\quad$ Chimie, $18(10), \quad 1123-1133$. https://doi.org/https://doi.org/10.1016/j.crci.2015.03.013

Malamis, S., \& Katsou, E. (2013). A review on zinc and nickel adsorption on natural and modified zeolite , bentonite and vermiculite: Examination of process parameters, kinetics and isotherms. Journal of 
Hazardous Materials, 252-253, 428-461. https://doi.org/10.1016/j.jhazmat.2013.03.024

Margeta, K., Zabukovec, N., Siljeg, M., \& Farkas, A. (2013). Natural Zeolites in Water Treatment - How Effective is Their Use. Water Treatment. https://doi.org/10.5772/50738

Meng, Q., Chen, H., Lin, J., Lin, Z., \& Sun, J. (2017). Zeolite A synthesized from alkaline assisted pre-activated halloysite for efficient heavy metal removal in polluted river water and industrial wastewater. Journal of Environmental Sciences (China), 56, 254-262. https://doi.org/10.1016/j.jes.2016.10.010

Merrikhpour, H., \& Jalali, M. (2013). Comparative and competitive adsorption of cadmium, copper, nickel, and lead ions by Iranian natural zeolite. Clean Technologies and Environmental Policy, 15(2), 303-316. https://doi.org/10.1007/s10098-012-0522-1

Mitrogiannis, D., Psychoyou, M., Baziotis, I., Inglezakis, V. J., Koukouzas, N., Tsoukalas, N., ... Markou, G. (2017). Removal of phosphate from aqueous solutions by adsorption onto $\mathrm{Ca}(\mathrm{OH}) 2$ treated natural clinoptilolite. Chemical Engineering Journal, 320, 510-522. https://doi.org/10.1016/j.cej.2017.03.063

Mohammadian, Z., Rabieh, S., \& Zavvar, H. (2018). Preparation of Fe / activated carbon directly from Orange Peel and its application in removal of nitrate from aqueous solutions, 12(45), 41-50.

Motsi, T., Rowson, N. A., \& Simmons, M. J. H. (2009). Adsorption of heavy metals from acid mine drainage by natural zeolite. International Journal of Mineral Processing, 92(1-2), 42-48. https://doi.org/10.1016/j.minpro.2009.02.005

Mourid, E., Lakraimi, M., El Khattabi, E., Benaziz, L., \& Berraho, M. (2017). Removal of textile dye acid green 1 from wastewater by activated carbon. Journal of Materials and Environmental Science, 8(9), 3121-3130. Retrieved from http://www.jmaterenvironsci.com/

Moussout, H., Ahlafi, H., Aazza, M., \& Maghat, H. (2018). Critical of linear and nonlinear equations of pseudofirst order and pseudo-second order kinetic models. Karbala International Journal of Modern Science, 4(2), 244-254. https://doi.org/10.1016/j.kijoms.2018.04.001

Panayotova, M. I. (2001). Kinetics and thermodynamics of copper ions removal from wastewater by use of zeolite. Waste Management, 21(7), 671-676. https://doi.org/10.1016/S0956-053X(00)00115-X

Park, D., Yun, Y.-S., \& Park, J. M. (2010). The past, present, and future trends of biosorption. Biotechnology and Bioprocess Engineering, 15(1), 86-102. https://doi.org/10.1007/s12257-009-0199-4

Paul, B., Dynes, J. J., \& Chang, W. (2017). Modified zeolite adsorbents for the remediation of potash brineimpacted groundwater: Built-in dual functions for desalination and $\mathrm{pH}$ neutralization. Desalination, 419(January), 141-151. https://doi.org/10.1016/j.desal.2017.06.009

Rajabi, M., Mirza, B., Mahanpoor, K., Mirjalili, M., Najafi, F., Moradi, O., ... Gupta, V. K. (2016). Adsorption of malachite green from aqueous solution by carboxylate group functionalized multi-walled carbon nanotubes: Determination of equilibrium and kinetics parameters. Journal of Industrial and Engineering Chemistry, 34, 130-138. https://doi.org/10.1016/j.jiec.2015.11.001

Rangabhashiyam, S., Anu, N., Giri Nandagopal, M. S., \& Selvaraju, N. (2014). Relevance of isotherm models in biosorption of pollutants by agricultural byproducts. Journal of Environmental Chemical Engineering, 2(1), 398-414. https://doi.org/10.1016/j.jece.2014.01.014

Sahimi, M. (2011). Flow and transport in porous media and fractured rock: from classical methods to modern approaches. (J. W. \& Sons, Ed.).

Santos, R. M. M. dos, Gonçalves, R. G. L., Constantino, V. R. L., Santilli, C. V., Borges, P. D., Tronto, J., \& Pinto, F. G. (2017). Adsorption of Acid Yellow 42 dye on calcined layered double hydroxide: Effect of time, concentration, $\mathrm{pH}$ and temperature. Applied Clay Science, 140, 132-139. https://doi.org/10.1016/j.clay.2017.02.005

Shahul Hameed, K., Muthirulan, P., \& Meenakshi Sundaram, M. (2017). Adsorption of chromotrope dye onto activated carbons obtained from the seeds of various plants: Equilibrium and kinetics studies. Arabian Journal of Chemistry, 10, S2225-S2233. https://doi.org/10.1016/j.arabjc.2013.07.058

Shukla, P. R., Wang, S., Ang, H. M., \& Tadé, M. O. (2009). Synthesis , characterisation , and adsorption evaluation of carbon-natural-zeolite composites. Advanced Powder Technology, 20(3), 245-250. https://doi.org/10.1016/j.apt.2009.02.006

Sogut, E. G., \& Caliskan, N. (2017). Isotherm and Kinetic Studies of Pb(II) Adsorption on Raw and Modified Diatomite by Using Non-Linear Regression Method. Fresenius Environmental Bulletin, 26(April), 27212729. Retrieved from https://www.researchgate.net/publication/316276207

Sprynskyy, M., Buszewski, B., Terzyk, A. P., \& Namiesnik, J. (2006). Study of the selection mechanism of heavy metal $(\mathrm{Pb} 2+, \mathrm{Cu} 2+, \mathrm{Ni} 2+$, and $\mathrm{Cd} 2+)$ adsorption on clinoptilolite. Journal of Colloid and Interface Science, 304, 21-28. https://doi.org/10.1016/j.jcis.2006.07.068

Subramani, S. E., \& Thinakaran, N. (2017). Isotherm, kinetic and thermodynamic studies on the adsorption behaviour of textile dyes onto chitosan. Process Safety and Environmental Protection, 106, 1-10. https://doi.org/10.1016/j.psep.2016.11.024

Sun, D., Zhang, Z., Wang, M., \& Wu, Y. (2013). Adsorption of Reactive Dyes on Activated Carbon Developed 
from Enteromorpha prolifera. American Journal of Analytical Chemistry, 04(07), 17-26. https://doi.org/10.4236/ajac.2013.47A003

Taamneh, Y., \& Sharadqah, S. (2017). The removal of heavy metals from aqueous solution using natural Jordanian zeolite. Applied Water Science, 7(4), 2021-2028. https://doi.org/10.1007/s13201-016-0382-7

Tabassi, D., Harbi, S., Louati, I., \& Hamrouni, B. (2017). Response surface methodology for optimization of phenol adsorption by activated carbon: Isotherm and kinetics study. Indian Journal of Chemical Technology, 24(3), 239-255.

Tran, H. N., You, S. J., \& Chao, H. P. (2016). Thermodynamic parameters of cadmium adsorption onto orange peel calculated from various methods: A comparison study. Journal of Environmental Chemical Engineering, 4(3), 2671-2682. https://doi.org/10.1016/j.jece.2016.05.009

Valdés, H., Tardón, R. F., \& Zaror, C. A. (2010). Effect of Zeolite Chemical Surface Properties on Catalytic Ozonation of Methylene Blue Contaminated Waters. Ozone: Science \& Engineering, 32(5), 344-348. https://doi.org/10.1080/01919512.2010.501197

Vijayaraghavan, K., Padmesh, T. V. N., Palanivelu, K., \& Velan, M. (2006). Biosorption of nickel(II) ions onto Sargassum wightii: Application of two-parameter and three-parameter isotherm models. Journal of Hazardous Materials, 133(1-3), 304-308. https://doi.org/10.1016/j.jhazmat.2005.10.016

Wang, S., \& Peng, Y. (2010a). Natural zeolites as effective adsorbents in water and wastewater treatment. Chemical Engineering Journal, 156(1), 11-24. https://doi.org/10.1016/j.cej.2009.10.029

Wang, S., \& Peng, Y. (2010b). Natural zeolites as effective adsorbents in water and wastewater treatment. Chemical Engineering Journal, 156(1), 11-24. https://doi.org/10.1016/J.CEJ.2009.10.029

Wang, X., Ozdemir, O., Hampton, M. A., Nguyen, A. V., \& Do, D. D. (2012). The effect of zeolite treatment by acids on sodium adsorption ratio of coal seam gas water. Water Research, 46(16), 5247-5254. https://doi.org/10.1016/j.watres.2012.07.006

Wu, F. C., Liu, B. L., Wu, K. T., \& Tseng, R. L. (2010). A new linear form analysis of Redlich-Peterson isotherm equation for the adsorptions of dyes. Chemical Engineering Journal, 162(1), 21-27. https://doi.org/10.1016/j.cej.2010.03.006

Wu, Y., \& Wang, L. (2016). Kinetic and Thermodynamic Studies of the Biosorption of Ni(II) by Modified Rape Straw. Procedia Environmental Sciences, 31, 75-80. https://doi.org/10.1016/j.proenv.2016.02.010

Xiyili, H., Çetintaş, S., \& Bingöl, D. (2017). Removal of some heavy metals onto mechanically activated fly ash: Modeling approach for optimization, isotherms, kinetics and thermodynamics. Process Safety and Environmental Protection, 109, 288-300. https://doi.org/10.1016/j.psep.2017.04.012

Yagub, M. T., Sen, T. K., Afroze, S., \& Ang, H. M. (2014). Dye and its removal from aqueous solution by adsorption: A review. Advances in Colloid and Interface Science, 209, 172-184. https://doi.org/10.1016/j.cis.2014.04.002

Zanin, E., Scapinello, J., de Oliveira, M., Rambo, C. L., Franscescon, F., Freitas, L., ... Dal Magro, J. (2017). Adsorption of heavy metals from wastewater graphic industry using clinoptilolite zeolite as adsorbent. Process Safety and Environmental Protection, 105, 194-200. https://doi.org/https://doi.org/10.1016/j.psep.2016.11.008

Zavareh, S., Farrokhzad, Z., \& Darvishi, F. (2018). Modification of zeolite 4A for use as an adsorbent for glyphosate and as an antibacterial agent for water. Ecotoxicology and Environmental Safety, 155(February), 1-8. https://doi.org/https://doi.org/10.1016/j.ecoenv.2018.02.043

Zendelska, A., Golomeova, M., Blazev, K., Krstev, B., \& Golomeov, B. (2014). Equilibrium Studies of Zinc Ions Removal from Aqueous Solutions by Adsorption on Natural Zeolite. Journal of Materials and Engineering, 4(7), 202-208. Retrieved from http://eprints.ugd.edu.mk/id/eprint/11369

Zhang, Y., Jin, F., Shen, Z., Lynch, R., \& Al-Tabbaa, A. (2018). Kinetic and equilibrium modelling of MTBE (methyl tert-butyl ether) adsorption on ZSM-5 zeolite: Batch and column studies. Journal of Hazardous Materials, 347, 461-469. https://doi.org/https://doi.org/10.1016/j.jhazmat.2018.01.007

Zheng, C., \& Bennett, G. D. (2002). Applied contaminant transport modeling (Vol. 2). Wiley-Interscience New York.

Zhou, K., Yang, Z., Liu, Y., \& Kong, X. (2015). Kinetics and equilibrium studies on biosorption of Pb(II) from aqueous solution by a novel biosorbent: Cyclosorus interruptus. Journal of Environmental Chemical Engineering, 3(3), 2219-2228. https://doi.org/https://doi.org/10.1016/j.jece.2015.08.002 